\title{
¿Seasonal Atmospheric Responses to Reduced Arctic Sea Ice in an Ensemble of Coupled Model Simulations
}

\author{
Tido Semmler, ${ }^{a}$ Lukrecia Stulic, ${ }^{\mathrm{a}}$ Thomas Jung,,${ }^{\mathrm{a}, \mathrm{b}}$ NATAlia Tilinina, \\ CAmila CAMPos, ${ }^{\mathrm{a}}$ Sergey GuleV,${ }^{\mathrm{c}}$ AND DARKo KoraCiN ${ }^{\mathrm{d}, \mathrm{e}}$ \\ ${ }^{a}$ Alfred Wegener Institute, Helmholtz Centre for Polar and Marine Research, Bremerhaven, Germany \\ ${ }^{\mathrm{b}}$ University of Bremen, Bremen, Germany \\ ${ }^{\mathrm{c}}$ P. P. Shirshov Institute of Oceanology, Moscow, Russia \\ ${ }^{\mathrm{d}}$ Physics Department, Faculty of Science, University of Split, Split, Croatia \\ e Division of Atmospheric Sciences, Desert Research Institute, Reno, Nevada
}

(Manuscript received 20 August 2015, in final form 4 March 2016)

\begin{abstract}
Arctic sea ice decline is expected to continue throughout the twenty-first century as a result of increased greenhouse gas concentrations. Here we investigate the impact of a strong Arctic sea ice decline on the atmospheric circulation and low pressure systems in the Northern Hemisphere through numerical experimentation with a coupled climate model. More specifically, a large ensemble of 1-yr-long integrations, initialized on 1 June with Arctic sea ice thickness artificially reduced by $80 \%$, is compared to corresponding unperturbed control experiments. The sensitivity experiment shows an ice-free Arctic from July to October; during autumn the largest near-surface temperature increase of about $15 \mathrm{~K}$ is found in the central Arctic, which goes along with a reduced meridional temperature gradient, a decreased jet stream, and a southward shifted Northern Hemisphere storm track; and the near-surface temperature response in winter and spring reduces substantially due to relatively fast sea ice growth during the freezing season. Changes in the maximum Eady growth rate are generally below $5 \%$ and hardly significant, with reduced vertical wind shear and reduced vertical stability counteracting each other. The reduced vertical wind shear manifests itself in a decrease of synoptic activity by up to $10 \%$ and shallower cyclones while the reduced vertical stability along with stronger diabatic heating due to more available moisture may be responsible for the stronger deepening rates and thus faster cyclone development once a cyclone starts to form. Furthermore, precipitation minus evaporation decreases over the Arctic because the increase in evaporation outweighs that for precipitation, with implications for the ocean stratification and hence ocean circulation.
\end{abstract}

\section{Introduction}

September Arctic sea ice extent has declined by $40 \%$ over the last three decades (Perovich et al. 2014) and September Arctic sea ice thickness has decreased by 85\% from 1975 to 2012 (Lindsay and Schweiger 2015). Also in the other seasons massive decreases in extent and thickness have been observed. What impacts could this have on the midlatitudes? There is already a

¿ Denotes Open Access content.

Corresponding author address: Tido Semmler, Alfred Wegener Institute, Helmholtz Centre for Polar and Marine Research, Am Handelshafen 12, 27570 Bremerhaven, Germany.

E-mail: tido.semmler@awi.de multitude of both observational and modeling studies that address the impact of recent and future Arctic sea ice decline on the large-scale circulation and related weather and climate in the Northern midlatitudes [see review papers by Budikova (2009), Petoukhov and Semenov (2010), Bader et al. (2011), Vihma (2014), Walsh (2014), and Cohen et al. (2014), and references therein]. Some studies attribute recent extreme winter conditions in the United States and in Eurasia to largescale circulation changes due to the record low Arctic sea ice extents in recent years (e.g., Francis and Vavrus 2012; Honda et al. 2009). However, there is an ongoing debate about to what extent such changes can be attributed to Arctic sea ice decline or explained by largescale intrinsic variability of the climate system (Screen et al. 2013). 
Observational studies have the caveat of including a variety of local and remote factors such as midlatitude influences. As a result it is difficult to disentangle different influencing factors. Furthermore, reliable observations of the Arctic sea ice extent are restricted to the satellite era spanning the last 30 to 40 years and longterm observations of the Arctic sea ice thickness are sparse and subject to considerable uncertainty (Lindsay and Schweiger 2015). It is challenging, therefore, to understand the origin of recent changes by observational studies alone. Consequently, it remains unclear whether recent atmosphere circulation changes in $\mathrm{Eu}$ rope and North America can be attributed to the Arctic sea ice decline, to local or remote diabatic heating and associated altered air-sea fluxes (Gulev et al. 2013), or to the inherent variability due to lower-latitude dynamics (Perlwitz et al. 2015).

Most but not all modeling studies published so far use atmosphere-only climate models to investigate the impact of Arctic sea ice decline on the weather and climate of the midlatitudes (e.g., Deser et al. 2007, 2010; Semmler et al. 2012; Screen et al. 2013; Peings and Magnusdottir 2014). More recently, the atmospheric response to Arctic sea ice decline has been studied from a numerical weather prediction (NWP) perspective by investigating the transient atmospheric response to sudden changes in the Arctic sea ice conditions in very large ensembles of short-term simulations of only a few weeks (Semmler et al. 2016). Finally, Arctic lowerlatitude linkages have recently been studied by carrying out experiments with and without relaxation of the Arctic atmosphere toward reanalysis data and by considering differences in midlatitude medium-range and subseasonal prediction skill (Jung et al. 2014).

Using atmosphere-only models has the advantage that the impact of sea ice changes can be assessed by prescribing observed or idealized sea ice distributions. The same advantage holds for experiments with atmosphere models coupled to slab ocean models such as in Rind et al. (1995) or Chiang and Bitz (2005). However, in the atmosphere-only simulations it is impossible to account for coupled processes in the response to Arctic sea ice decline and in the ones using slab ocean models only thermodynamic feedbacks are considered while ocean dynamics is missing. Therefore, idealized coupled sensitivity experiments using full ocean and interactive sea ice models have been performed by Scinocca et al. (2009), Deser et al. (2015), and Petrie et al. (2015). While the first two studies of the three use long-term simulations on the order of hundreds of years, the latter study employs ensembles of 1-yr simulations-an approach we are using in the present study although with important differences in the sea ice perturbations as pointed out in section 2a. Also Tietsche et al. (2011) use a similar experimental setup, but with a different focus (recovery mechanism of Arctic sea ice).

We performed two sets of experiments with and without reduction of Arctic sea ice thickness by $80 \%$ on 1 June for a large number of different initial states drawn from a long control integration of the coupled model. We study the ensemble mean response of the coupled system during the 12-month period following the introduction of the perturbation in early summer. Note that the strongest perturbation occurs in summer and autumn because in late autumn strong freezing occurs in the sensitivity experiments, making the sensitivity experiments less different in winter and spring compared to summer and autumn. While this issue may result in comparably weak responses in winter and spring, the advantage of our method is that the model can run without adding any extra heat to the coupled system during the 1-yr simulations.

The aim of this study is to investigate the atmospheric response to reduced Arctic sea ice thickness and concentration by taking coupled processes into account. Our diagnostics will be focused on tropospheric temperature and precipitation changes as well as on characteristics of cyclone activity. The latter is considered to be an important indicator of changes in the coupled climate system, responding to the ocean signals (e.g., Woollings et al. 2012) and sea ice (e.g., Serreze and Barrett 2008), and can also modulate atmospheric influence on sea ice on shorter time scales (Zhang et al. 2013).

In section 2 the experiment setup and the cyclone tracking method are described. This is followed by the presentation of the results in section 3. Finally, the implications of our results are discussed in section 4 .

\section{Methodology}

\section{a. Model setup}

We use the AWI-CM (Alfred Wegener Institute Climate Model) consisting of the multiresolution Finite Element Sea Ice Ocean Model (FESOM) developed at AWI (Wang et al. 2014) and the atmosphere model ECHAM6 developed at Max Planck Institute for Meteorology (Stevens et al. 2013). This coupled atmosphere-ocean-sea ice model has been shown to be of comparable performance in simulating present-day climate and its variability to state-of-the-art coupled climate models that took part in phase 5 of the Coupled Model Intercomparison Project (CMIP5) (Sidorenko et al. 2015; Rackow et al. 2015, manuscript submitted to Climate Dyn.). 
We use ECHAM6 in the standard resolution of T63L47 corresponding to about $200 \mathrm{~km}$ horizontally with 47 vertical levels up to $0.01 \mathrm{hPa}$ (about $80 \mathrm{~km}$ ) coupled to FESOM with a horizontal ocean grid resolution between 25 and $150 \mathrm{~km}$ and 46 vertical levels as defined in Sidorenko et al. (2015). The coupling software used is OASIS3-MCT (Valcke et al. 2013).

The 1500-yr-long control simulation with constant 1990 greenhouse gas and aerosol concentration forcing, which is described and evaluated by Rackow et al. (2015, manuscript submitted to Climate Dyn.), has been extended by 100 years. On 1 June of each of those 100 years a $1-y r$ control simulation initialized with data of that day of that year (referred to as CTL) has been run. A corresponding 1-yr sensitivity simulation with the same initialization data but $80 \%$ reduced sea ice thickness in the Arctic (referred to as RED) has also been performed. In the beginning of each sensitivity simulation the sea ice extent is unchanged compared to the corresponding reference run but will be lower throughout the rest of the simulation due to melting processes and delayed onset of freezing. Altogether we have a 100-member CTL and a 100-member RED ensemble. In these ensemble simulations the enforcement of the global flux conservation as described in Sidorenko et al. (2015) has been switched off. This has been done to avoid possible spurious teleconnections associated with the correction of the global flux. The minor nonconservation of the global flux caused by different model geometries may be neglected on the discussed time scales. The design of the experiments allows analyzing the response of large-scale atmospheric circulation, freshwater balance, and cyclone characteristics to the modified ice conditions during the 1 -yr period starting on 1 June of each year in 100 ensemble members.

\section{b. Cyclone tracking}

Cyclone tracking was performed using the numerical algorithm of Zolina and Gulev (2002) and Zolina and Gulev (2003) on a polar orthographic projection with $181 \times 181$ grid points (centered at the North Pole), allowing for effective cyclone identification north of $25^{\circ} \mathrm{N}$. The original AWI-CM SLP data were interpolated onto the polar orthographic grid using the modified method of local procedures (Akima 1970).

Postprocessing of the output of tracking (coordinates, central pressure, and time) included the cutoff of the cyclones with less than 1-day lifetime and shorter than 1000-km migration distances. Furthermore we applied filtering unrealistic cyclone trajectories over the mountain regions by removing trajectories reaching their maximum depth in the areas higher than $1500 \mathrm{~m}$.
To effectively map cyclone numbers and frequencies, 6-hourly trajectories were interpolated linearly onto 10 -min time steps. This process eliminates underestimation of the number of cyclones and random errors in cyclone frequencies that can occur when this procedure is not applied (Zolina and Gulev 2002). Mapping of cyclone numbers and frequencies is performed for the grid with circular cells equivalent to $155000 \mathrm{~km}^{2}$ ( $2^{\circ}$ latitude) as in Tilinina et al. (2013). This numerical methodology was extensively evaluated during the IMILAST project (Neu et al. 2013) and was also successfully applied for the comparative assessment of cyclone activity in different reanalyses (Tilinina et al. 2013), operational products in different resolutions (Jung et al. 2006), climate model simulations (Löptien et al. 2008), and idealized atmospheric models (Kravtsov and Gulev 2013).

\section{Results}

\section{a. Sea ice}

Figure 1 shows the development of the sea ice area and Fig. 2 of the sea ice volume month by month as an average over the ensembles of CTL and RED experiments, respectively, from the initialization month to the end of the year-long simulations. The Arctic is completely free of ice (sea ice area less than $10^{6} \mathrm{~km}^{2}$ ) for four months (July-October) in all members of the RED simulations, which is expected to happen around the year 2100 when considering CMIP5 projections under the strong RCP8.5 emissions scenario (Hezel et al. 2014, their Fig. 5). This is a strong perturbation compared to the one in Petrie et al. (2015). Their perturbation was designed to yield sea ice conditions similar to the observed conditions in the low ice extent years 2007 and 2012.

Despite our strong perturbation, already in February the sea ice areas of the ensembles of CTL and RED simulations are close to each other (less than $5 \%$ relative difference) with the error bars overlapping. This means that the sea ice area recovers at the end of the winter and remains practically the same as in the case when no sea ice has been taken away. However, this is not the case for the sea ice volume, which is distinctively different during the entire year of the simulation (e.g., February differences are about $25 \%$ ). While thin sea ice can form quickly in the entire Arctic during the winter it cannot recover its thickness. The fact that changes in the sea ice area are comparably small in winter and spring should be considered when interpreting the results for those seasons. It should be noted that observations over the past 32 years show a similar behavior (Keen et al. 2013). Therefore, investigating responses to strong 

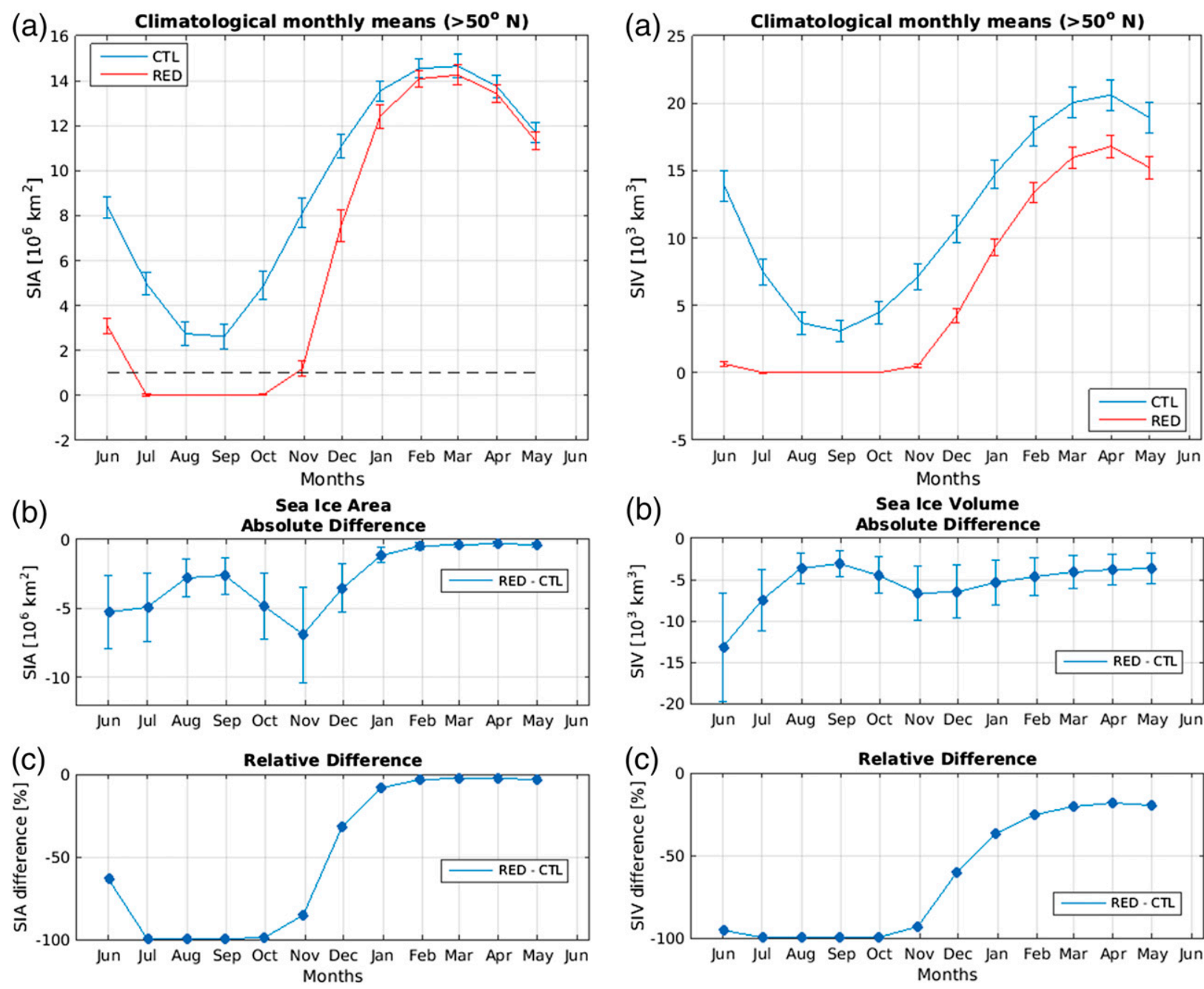

FIG. 1. (a) Sea ice area in the CTL and RED experiments. (b) Absolute and (c) relative difference RED minus CTL experiments. The gray dashed line in (a) indicates the level below which the Arctic is regarded as sea ice free. The error bars in (a) indicate the standard deviation from the 100 ensemble members of CTL and RED, respectively. The error bars in (b) indicate the standard deviation from the 100 differences of each pair RED minus CTL.

summer-autumn sea ice declines and weak winterspring sea ice declines is relevant.

\section{b. Surface energy budget and surface temperature}

The changes in sea ice have substantial impacts on the surface energy budget. Radiative heat flux changes are most pronounced over the Arctic Ocean in summer [July-September (JAS)] and autumn [October-December (OND)] and relatively weak in winter [January-March (JFM)] (Fig. 3) - in line with the small sea ice area changes in the latter season. The downward anomalies in summer (mostly between 10 and $20 \mathrm{~W} \mathrm{~m}^{-2}$; see Fig. 3b) are due to the extra shortwave radiation absorbed by the ice-free

FIG. 2. (a) Sea ice volume in the CTL and RED experiments. (b) Absolute and (c) relative difference RED minus CTL experiments. The error bars in (a) indicate the standard deviation from the 100 ensemble members of CTL and RED, respectively. The error bars in (b) indicate the standard deviation from the 100 differences of each pair RED minus CTL.

ocean in the RED simulations. Longwave radiation changes (not shown) are minor in this season. It should be noted that those downward anomalies are even much stronger in June (mostly between 40 and $60 \mathrm{~W} \mathrm{~m}^{-2}$; not shown), which is not included in our summer average. The upward anomalies in autumn (mostly between 10 and $20 \mathrm{~W} \mathrm{~m}^{-2}$; see Fig. 3d) are due to the extra emission of longwave radiation due to the warmer surface temperatures (shown and discussed below). These upward anomalies weaken in winter (Fig. 3f) due to the weakening surface temperature anomalies.

Figure 4 shows the surface temperature response in summer, autumn, and winter. The response is strongest in autumn when the ocean emits the extra energy absorbed 
(a)

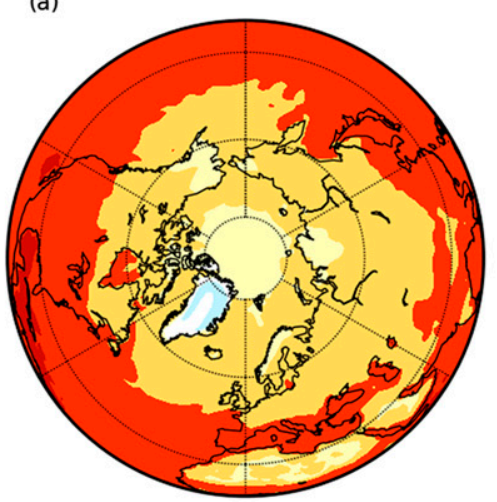

(c)

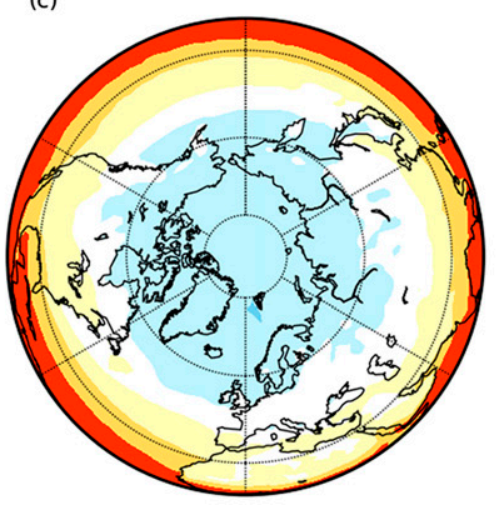

(e)

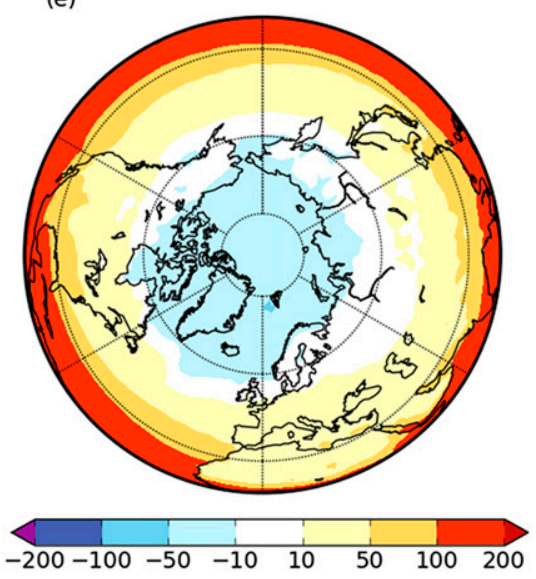

(b)

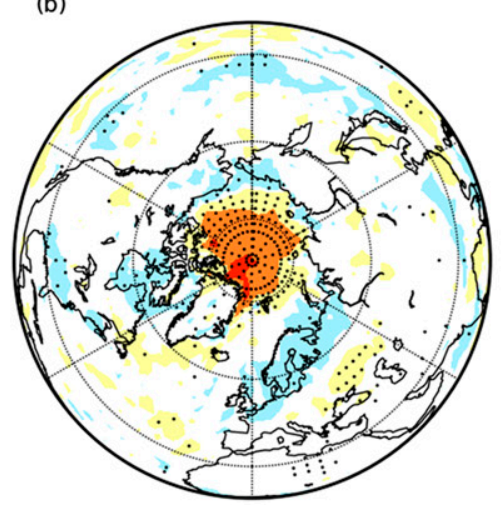

(d)

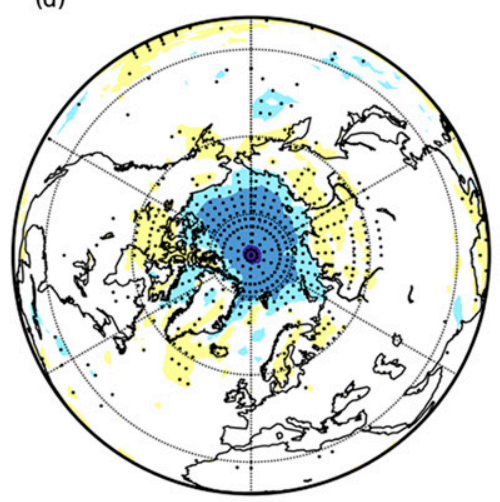

(f)

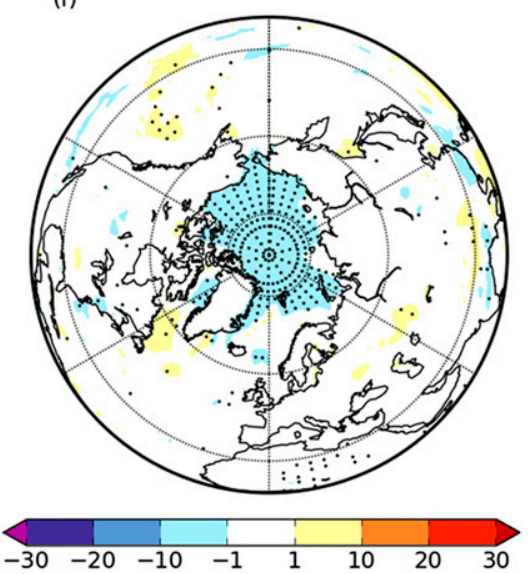

FIG. 3. Radiative surface heat fluxes (shortwave plus longwave, downward positive; $\mathrm{W} \mathrm{m}^{-2}$ ) in (a) CTL and (b) difference RED minus CTL for summer (JAS). (c), (d) As in (a), (b), but for autumn (OND). (e),(f) As in (a),(b), but for winter (JFM). In the difference plots the black dots indicate where the response is significant at the $95 \%$ level according to a Wilcoxon test.

during the summer in the RED simulations while the sea ice has started to regrow in the CTL simulations, leading to cold surface temperatures due to the insulating effect of the sea ice. Differences reach up to $15 \mathrm{~K}$ in the central Arctic. In fact, the strongest temperature difference was identified in November with up to $19 \mathrm{~K}$ in the central Arctic. This is the month with the strongest absolute difference in the sea ice extent (Fig. 1b).

The differences in turbulent surface heat fluxes (Fig. 5) are also strongest in the autumn season. In the CTL 
(a)

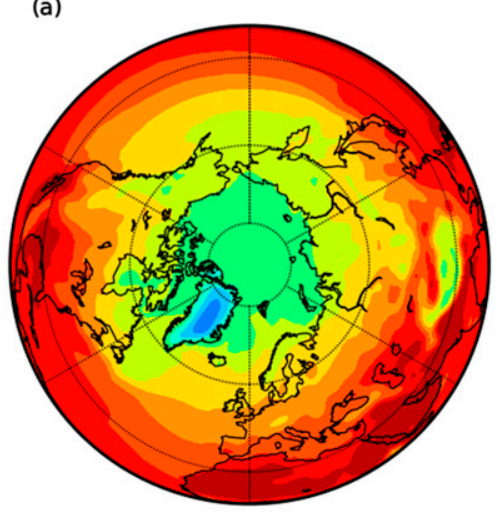

(c)

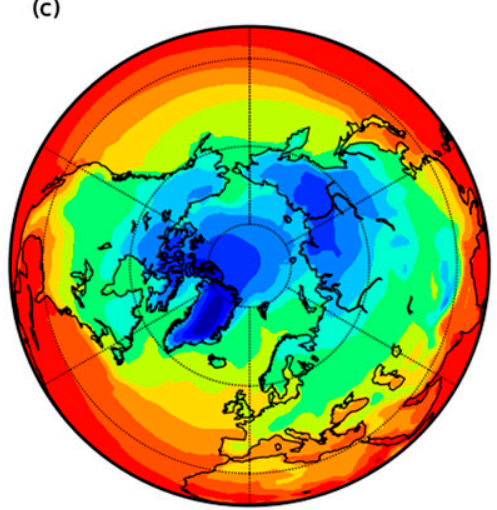

(e)

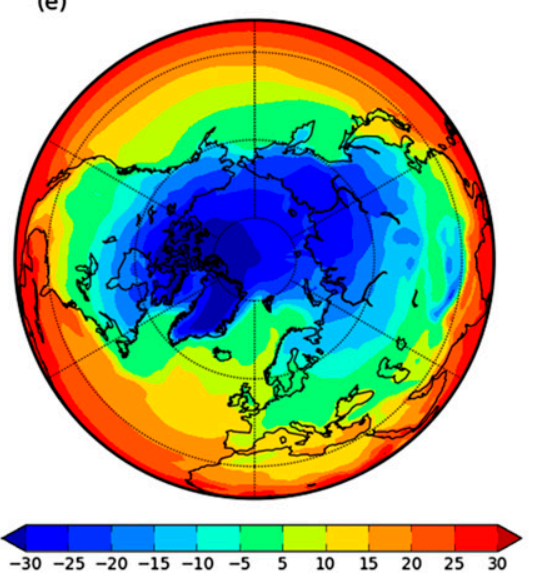

(b)

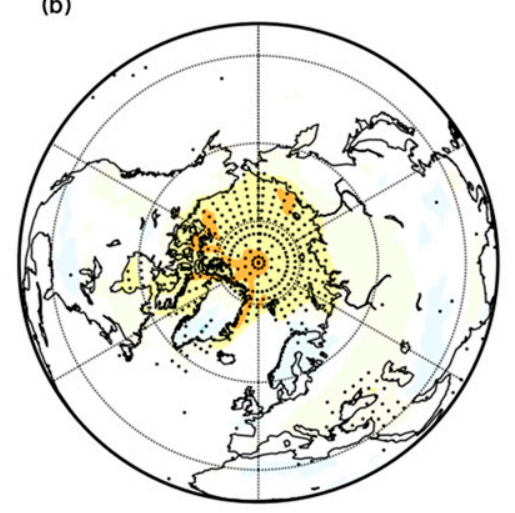

(d)

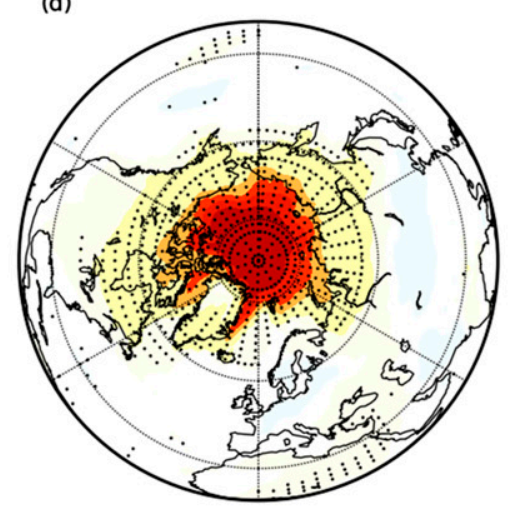

(f)

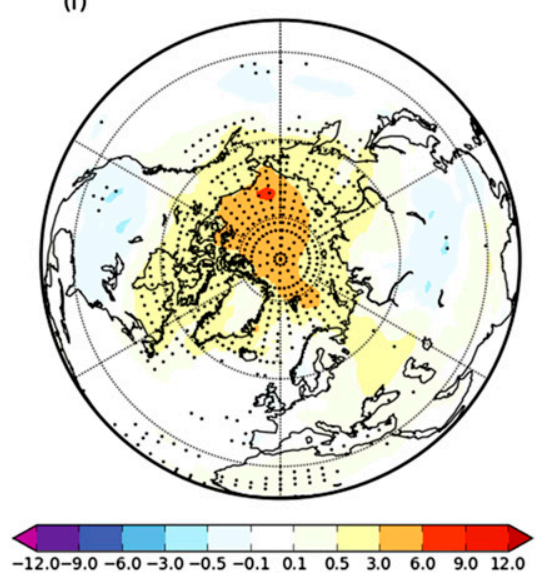

FIG. 4. Surface temperature $\left({ }^{\circ} \mathrm{C}\right)$ in (a) CTL and (b) difference RED minus CTL for summer (JAS). (c),(d) As in (a),(b), but for autumn (OND). (e),(f) As in (a),(b), but for winter (JFM). In the difference plots the black dots indicate where the response is significant at the $95 \%$ level according to a Wilcoxon test.

simulations turbulent surface heat fluxes over the Arctic are close to 0 in all seasons. In the RED simulations these fluxes turn slightly upward in summer and winter (in most areas between 1 and $10 \mathrm{~W} \mathrm{~m}^{-2}$ ) but substantially upward (around $30 \mathrm{~W} \mathrm{~m}^{-2}$ ) in autumn. It is also the autumn season that shows substantial downward flux anomalies of up to $30 \mathrm{~W} \mathrm{~m}^{-2}$ in the sea areas south of the Arctic Ocean, decreasing the upward fluxes in those areas compared to the CTL simulations, whereas in the other seasons such anomalies are not significant. 
(a)

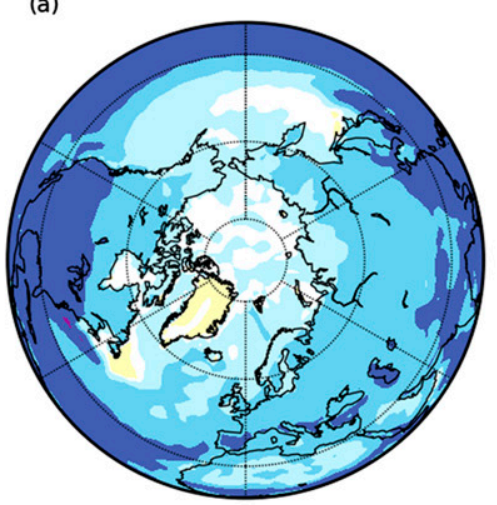

(c)

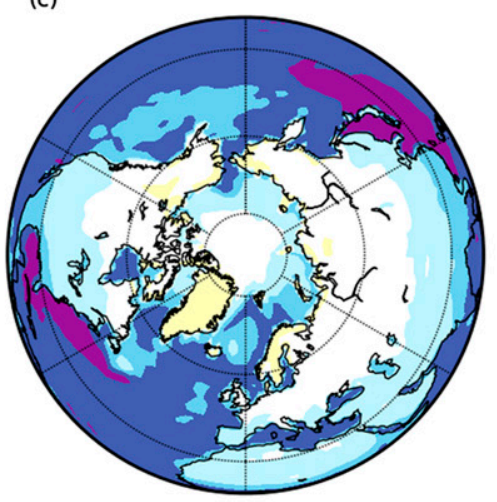

(e)
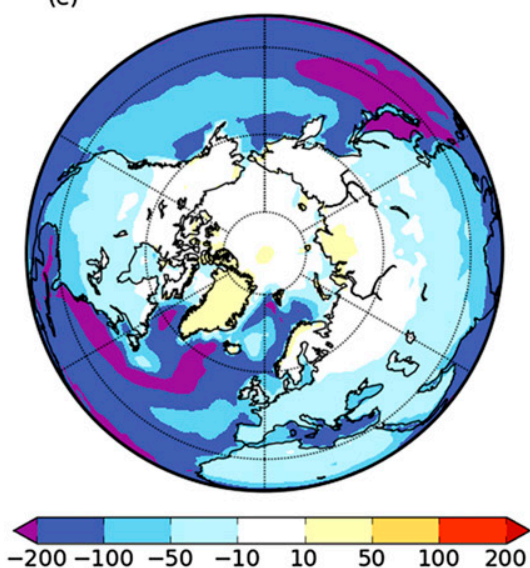

(b)

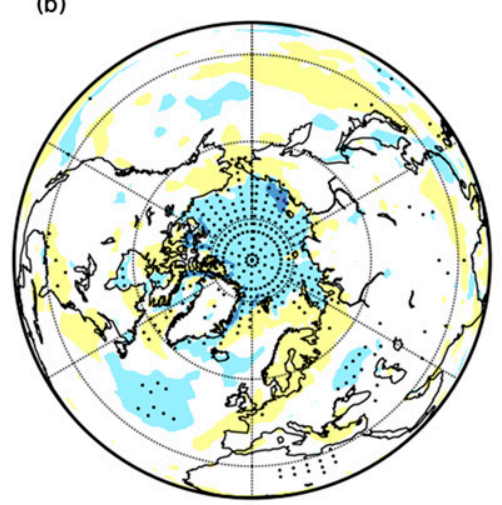

(d)

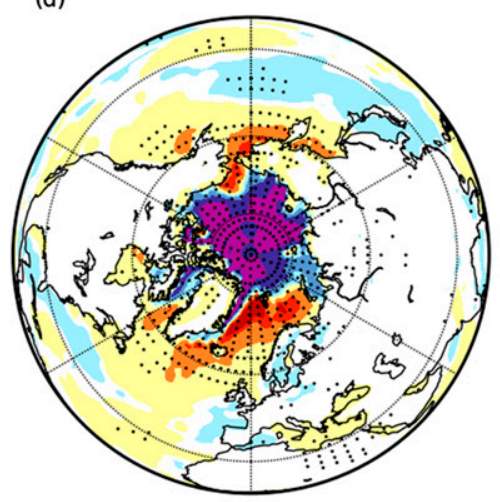

(f)

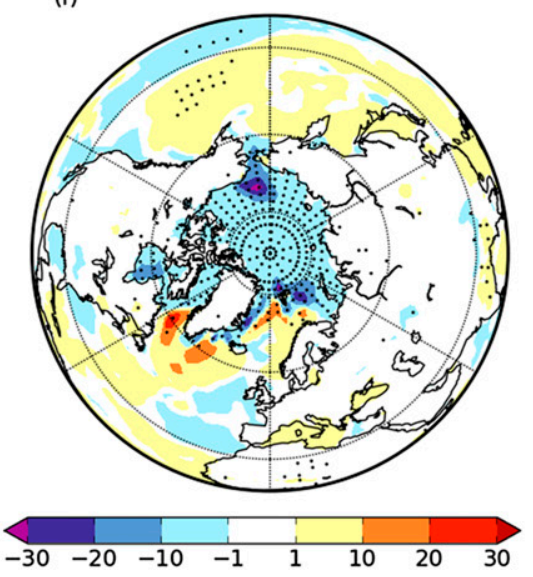

FIG. 5. Turbulent surface heat fluxes (sensible plus latent, downward positive; $\mathrm{W} \mathrm{m}^{-2}$ ) in (a) CTL and (b) difference RED minus CTL for summer (JAS). (c),(d) As in (a),(b), but for autumn (OND). (e),(f) As in (a),(b), but for winter (JFM). In the difference plots the black dots indicate where the response is significant at the $95 \%$ level according to a Wilcoxon test.

It is noteworthy that over northern North America and northeastern Asia the warming signal tends to spread out farther southward in autumn than in winter (Figs. 4d,f). Over North America this could be due to a shift in the circulation anomaly from northward advection in autumn to southward advection in winter
(Figs. 6d,f). Certainly the magnitude of the central Arctic warming is likely to play a role. Over the ocean areas the opposite is true (i.e., the warming signal tends to spread out farther southward in winter than in autumn) the downward turbulent surface heat flux anomalies in autumn may lead to a slow accumulation of heat in the 
(a)

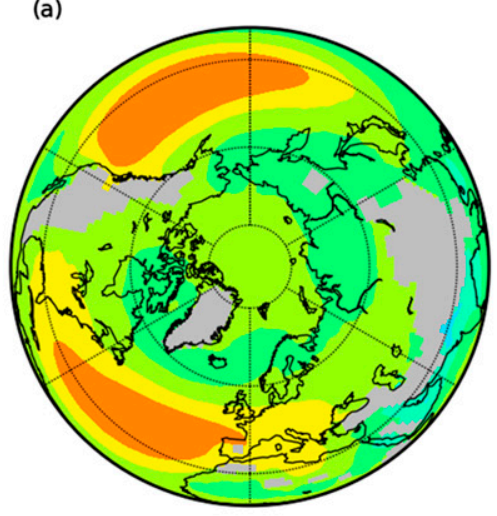

(c)

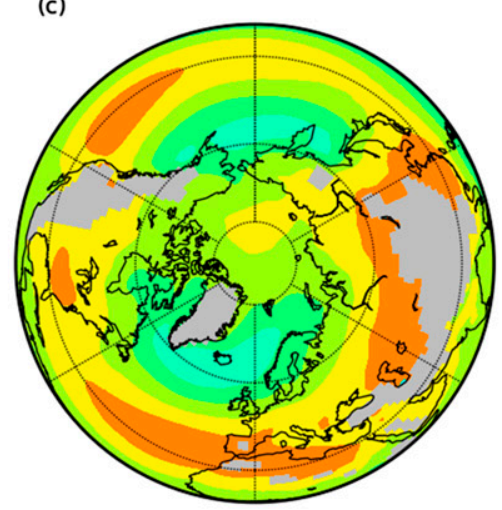

(e)

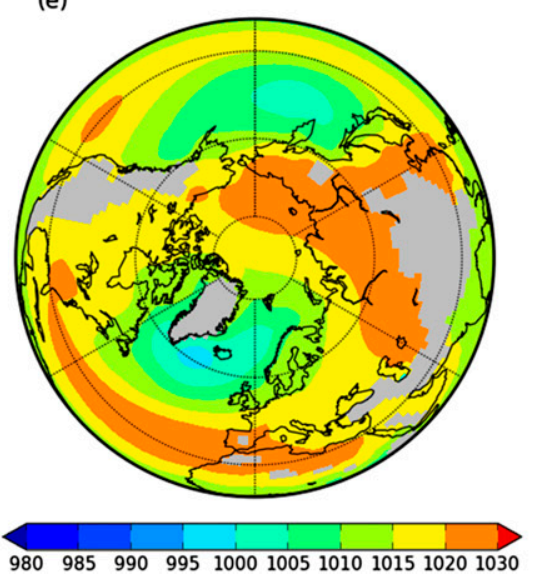

(b)

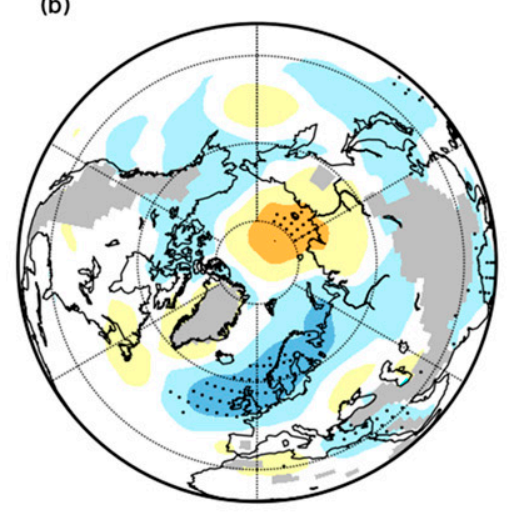

(d)

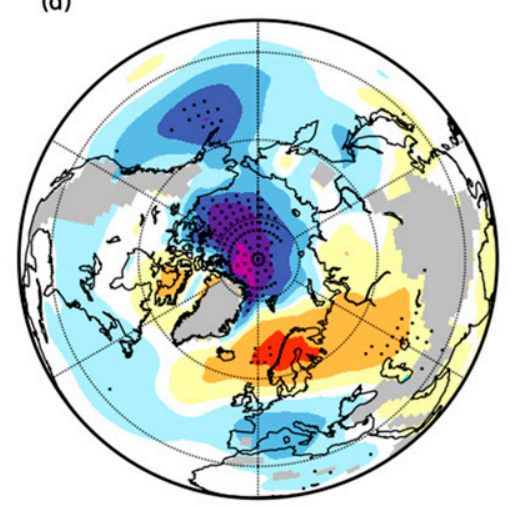

(f)

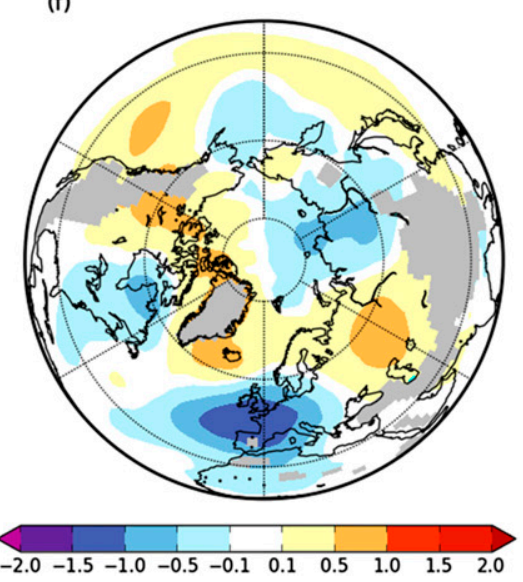

FIG. 6. Mean sea level pressure (hPa) in (a) CTL and (b) difference RED minus CTL for summer (JAS). (c),(d) As in (a),(b), but for autumn (OND). (e),(f) As in (a),(b), but for winter (JFM). Values are only shown for grid points where Earth's surface is below $1000 \mathrm{~m}$ above sea level to exclude unrealistic values due to extrapolation. In the difference plots the black dots indicate where the response is significant at the $95 \%$ level according to a Wilcoxon test.

ocean surface layer resulting in the stronger sea surface temperature anomalies in winter. Some autumn and winter cooling of up to around $0.5 \mathrm{~K}$, albeit hardly significant, is simulated in parts of North America and Siberia.

\section{c. Large-scale circulation}

Figure 6 shows the mean sea level pressure (MSLP) response. In summer anomalies are typically within $1 \mathrm{hPa}$ even though some of them are significant: over 
northern Europe negative anomalies and over the eastern Arctic positive anomalies can be seen. The strongest response is detected in autumn, which makes sense given that the surface forcing is strongest in that season. The sign of the response tends to be opposite compared to the summer response, although the positive anomalies over northern Europe are hardly significant and the negative anomalies are located more toward the western Arctic. In winter, when there are hardly any changes in the Arctic sea ice area, no significant changes in the MSLP distribution can be found.

Comparing Figs. 6 and 7, the latter showing the 500-hPa geopotential height (Z500), it becomes obvious that the summer response is barotropic (Figs. 6b and 7b). It leads to a strengthened westerly flow over Europe consistent with a positive phase of the North Atlantic Oscillation (NAO) along with a weakened westerly flow over parts of northern Asia.

In autumn the strong surface heating in the central Arctic leads to a baroclinic response with low anomalies close to the surface and high anomalies in the midtroposphere (cf. Figs. 6d and 7d). It should be noted that the described response actually acts to reduce the baroclinicity in the RED experiments compared to the CTL experiments because the baroclinic response has opposite sign to the actual baroclinicity in the CTL experiments. The anomalous heat low at the surface (or the weakening of the cold high at the surface) is consistent with increased upward turbulent surface heat fluxes and longwave radiation and a less stable situation. Vertical temperature anomaly profiles (Fig. 8) confirm that the strongest destabilization occurs in autumn. The anomalous surface heat is strongest and spreads out into the middle troposphere in contrast to the other seasons. Interestingly, in winter some significant stratospheric warming of partly more than $1 \mathrm{~K}$ close to the pole can be seen. Consistently, the 50-hPa geopotential height increases by more than $50 \mathrm{~m}$ around the pole (not shown), indicating a weaker stratospheric vortex. Such stratospheric winter response to reduced Arctic summerautumn sea ice is not new [see the review paper by Cohen et al. (2014)]. It may lead to colder winter surface temperatures in the midlatitudes - a feature we can also see from our simulations, albeit only weakly (Figs. 4d,f).

Over northeastern Europe a positive barotropic response and over the northern North Pacific a negative barotropic response can be seen in autumn (Figs. 6d and $7 \mathrm{~d}$ ). While in the midtroposphere a weakened westerly flow is simulated in the midlatitudes, this is only the case over northern Europe close to the surface. This may explain the fact that any continental surface cooling that may be expected due to a weakened westerly flow and an associated weaker maritime influence on the continents is only limited. Over the west coast of North America an anomalous southeasterly flow close to the surface can be seen. Over the Mediterranean area an increased westerly flow is identified. Both over Europe and over the North Pacific the pressure anomalies indicate a shift of the storm track to the south. This southward shift persists into winter over Europe but not over the North Pacific.

In winter there are small areas of significant Z500 responses that are similar to the corresponding insignificant MSLP responses (cf. Figs. 6f and 7f). The western Arctic experiences positive Z500 and MSLP anomalies while over Europe there is a dipole of negative anomalies over western Europe and positive anomalies over eastern Europe. The pattern resembles to some extent the negative phase of the east Atlantic/ western Russia pattern, also referred to as the Eurasian pattern type 1 in Barnston and Livezey (1987). These anomalies lead to a weakened westerly flow over North America and to an anomalous southerly flow over central Europe. Furthermore, like in autumn, the Mediterranean area tends to experience a stronger westerly flow. The winter surface anomaly pattern also resembles the positive phase of the Arctic dipole pattern, which is shown to have influence on sea ice motion such as increased Fram Strait ice export and enhanced sea ice import from the Laptev and East Siberian Seas into the Arctic basin (Wu et al. 2006).

\section{d. Hydrological cycle}

The anomalies of (liquid plus solid) precipitation minus evaporation $(P-E$; Fig. 9$)$ are negative over the Arctic in summer and especially autumn; in winter negative anomalies are restricted to the ice edge in the North Atlantic section and to the Beaufort Sea and Bering Strait. When considering precipitation and evaporation separately, it turns out that both fluxes increase over the Arctic in the sensitivity experiment (not shown) as is expected due to the sea ice loss, with the magnitude of the response for evaporation being larger than that for precipitation. This can have important implications for the near-surface salinity and the stratification of the Arctic Ocean. Whereas in summer more moisture is transported into northern Europe due to increased westerly flow leading to an increase in $P-E$ (Fig. 9b), in autumn and winter (Figs. 9d,f) there is a tendency of an increase in $P-E$ over the Mediterranean Sea due to an increased westerly flow in that area, with possible consequences for the salinity and stratification of the Mediterranean Sea. However, it should be noted that the $P-E$ response outside the Arctic is patchy and hardly significant.

There is an ongoing debate whether reduced Arctic sea ice would lead to increased snow cover in autumn 
(a)

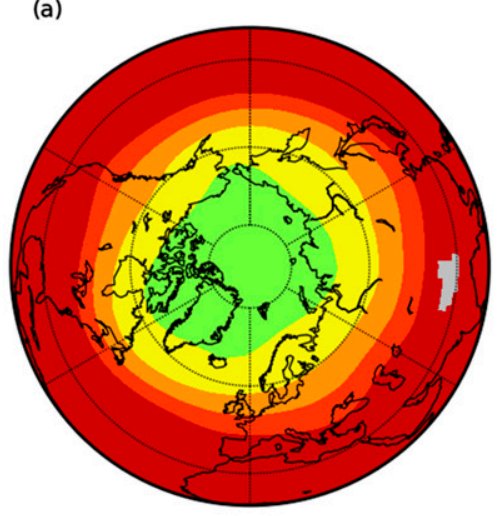

(c)

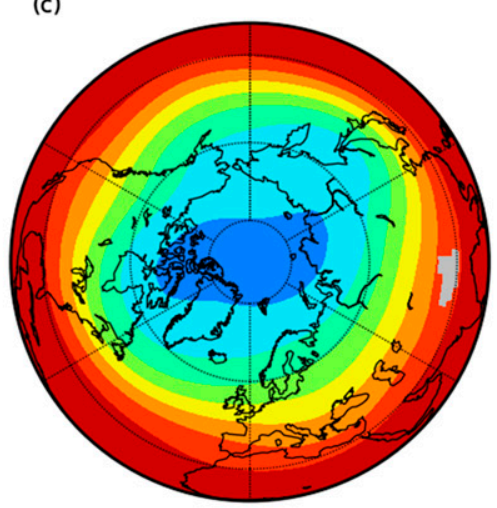

(e)

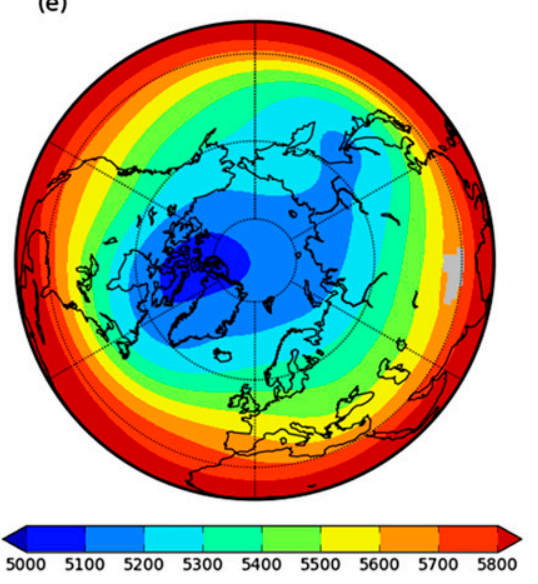

(b)

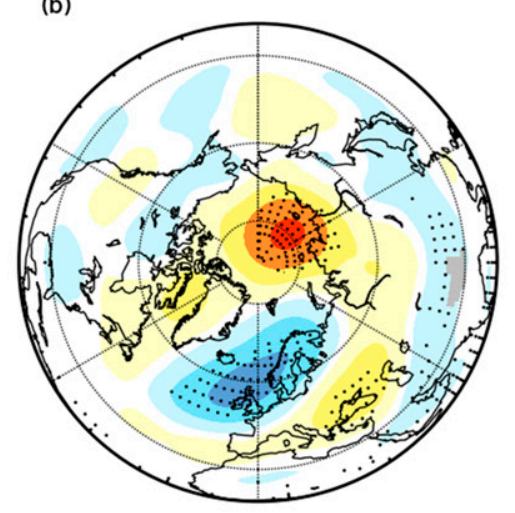

(d)

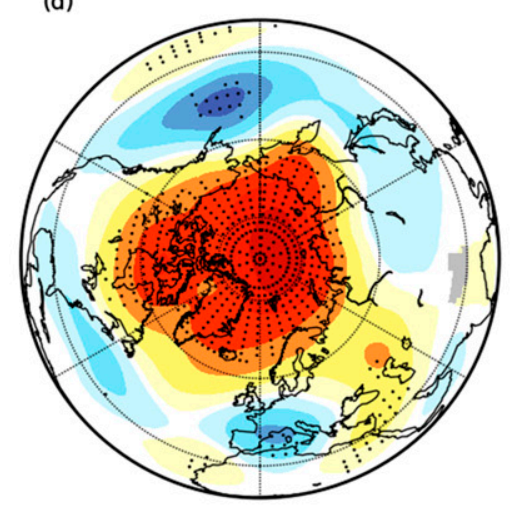

(f)

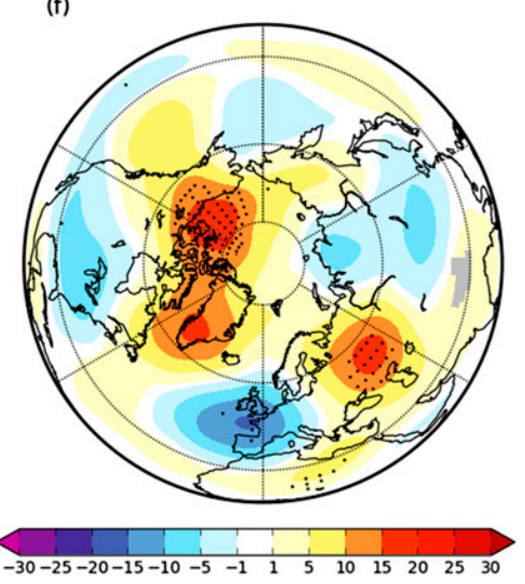

FIG. 7. 500-hPa geopotential height (m) in (a) CTL and (b) difference RED minus CTL for summer (JAS). (c),(d) As in (a),(b), but for autumn (OND). (e),(f) As in (a),(b), but for winter (JFM). Values are only shown for grid points where Earth's surface is below $5000 \mathrm{~m}$ above sea level to exclude unrealistic values due to extrapolation. In the difference plots the black dots indicate where the response is significant at the $95 \%$ level according to a Wilcoxon test.

over Siberia. This might trigger a negative phase of the NAO and Arctic Oscillation (AO) consistent with a southward shift of the storm track in the following winter, leading to cold Eurasian winters (Cohen et al. 2012, 2014). However, our results do not show any significant changes in autumn snow cover (Fig. 10), which is consistent with the patchy precipitation response. In contrast, in winter some significant snow thickness increases of up to $2 \mathrm{~cm}$ water equivalent are identified close to the Siberian coast, similar to Petrie 


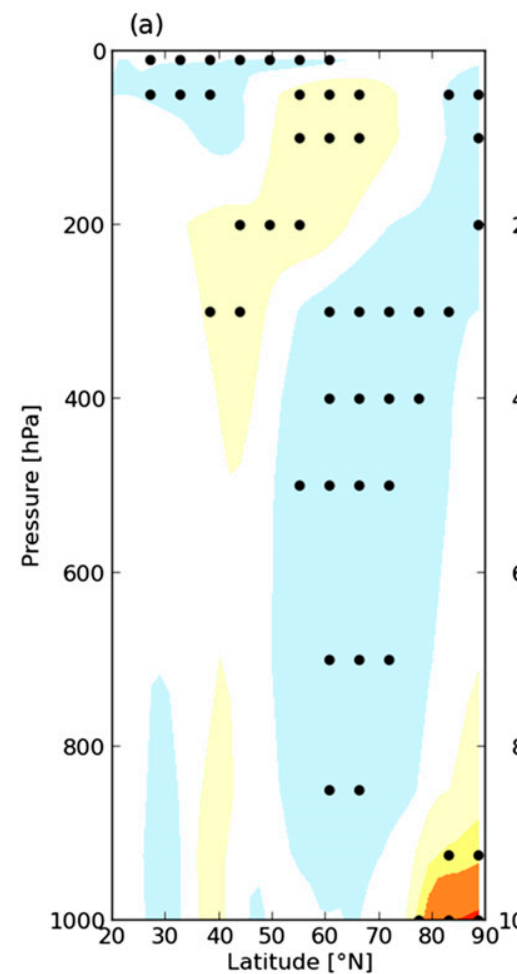

(b)
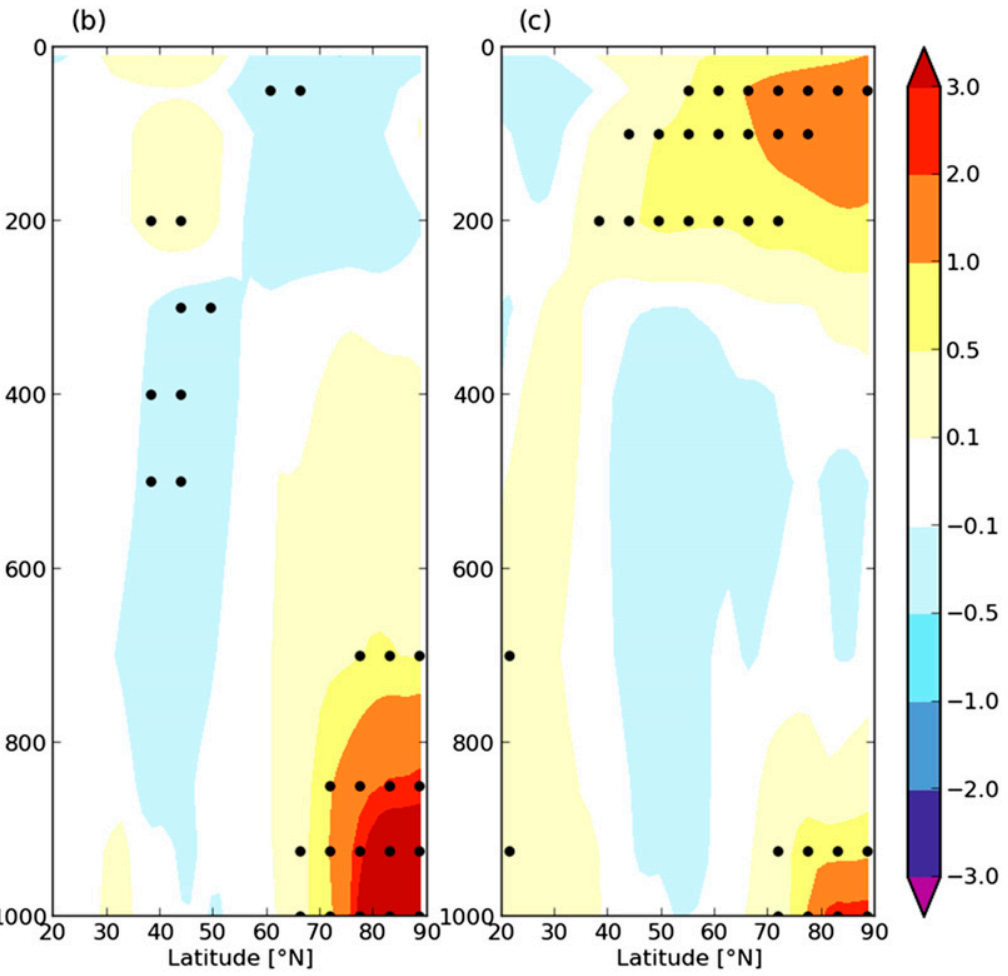

FIG. 8. Vertical cross section of response in zonally averaged temperature (RED minus CTL) for (a) JAS, (b) OND, and (c) JFM. Black dots indicate where the response is significant at the $95 \%$ level according to a Wilcoxon test.

et al. (2015). These changes occur when there is already a substantial snow cover so that large-scale circulation or storm track responses are not likely. The identified weakening of the stratospheric vortex and the slight winter cooling in some Eurasian areas as well as the storm track responses found in the following analyses are therefore not likely due to snow cover increases but are more likely a result of the decreased Arctic sea ice cover.

\section{e. Cyclones and storm tracks}

An important feature of the midlatitude atmospheric circulation, cyclone activity is closely related to diabatic signals associated with air-sea interaction processes (Neiman and Shapiro 1993; Rudeva and Gulev 2011), instability of the midlatitude flow potentially driven by intrinsic atmospheric variability, and general atmospheric circulation changes that may be controlled by changes in meridional temperature gradient. The most intense cyclogenesis occurs over the storm formation regions over western boundary currents and their extension regions, where strong surface air-sea fluxes force low-level baroclinic instability. Multiyear sea ice over the Arctic generally keeps the ocean and the atmosphere thermally isolated from each other. From this perspective the reduced sea ice cover and seasonally ice-free ocean in the RED experiments, along with the changes in the atmospheric circulation characteristics, may cause changes in cyclone activity. In the following, we analyze the response of extratropical cyclones to a reduction of Arctic sea ice.

A measure of synoptic activity is defined by Blackmon (1976) as standard deviation of high-pass-filtered Z500 data. Jung (2005) showed that a very simple high-pass filter considering only the difference between two consecutive 24-h time steps captures synoptic variations of up to 10 days. Here we define synoptic activity in the same way as Jung (2005) but for MSLP to be consistent with surface cyclone parameters shown later in this section. Patterns are similar between MSLP and Z500 synoptic activity. Figure 11 shows MSLP synoptic activity from CTL as well as MSLP synoptic activity responses for RED minus CTL.

In summer, changes are hardly matching statistical significance and consist of a slight extension of the North Atlantic storm track toward western Europe and of a decreasing synoptic activity over the eastern Mediterranean Sea as well as over northeastern Africa (Fig. 11b). Therefore, over the European sector a strengthening of the midlatitude storm track and a weakening of the subtropical one is identified. This signature is consistent with a positive NAO index (e.g., Osborn 2006) and 
(a)

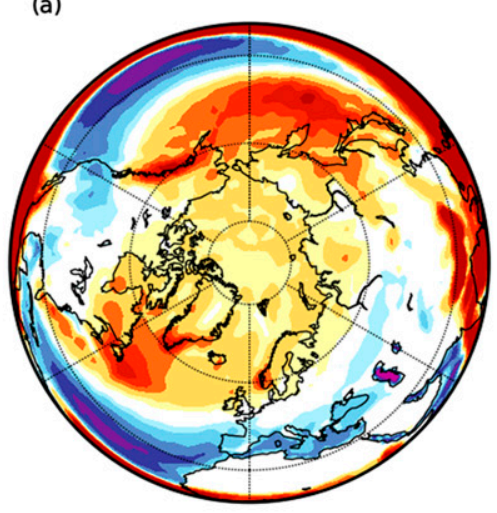

(c)

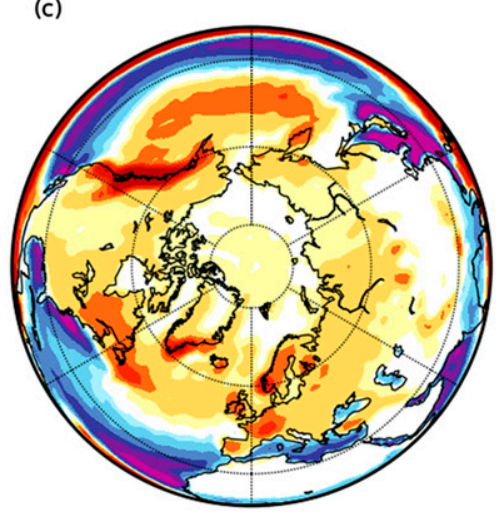

(e)

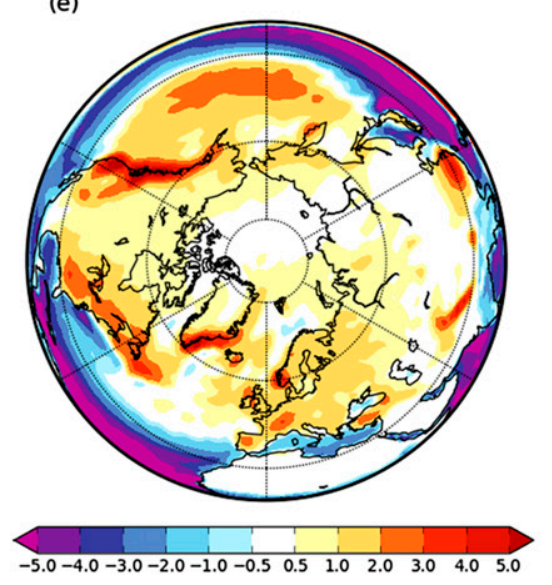

(b)

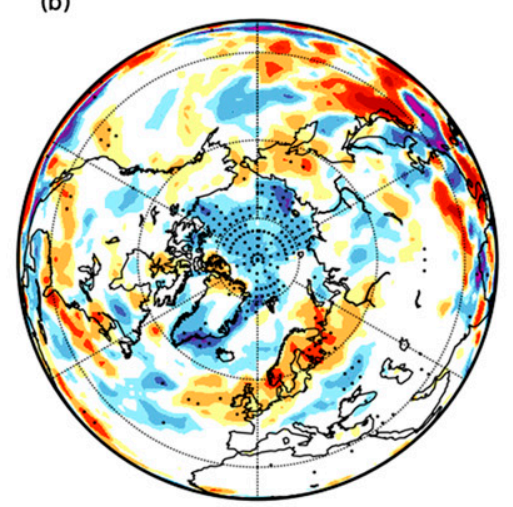

(d)

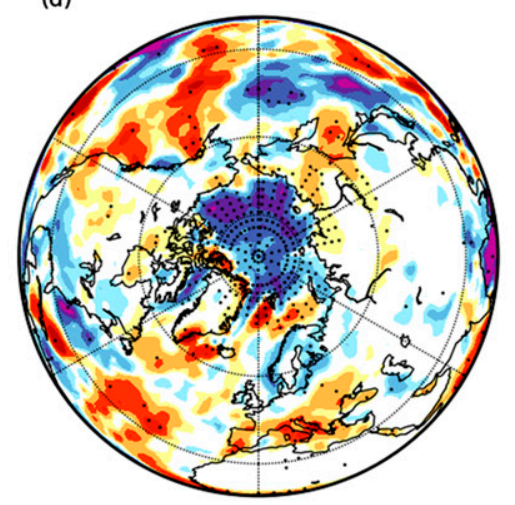

(f)

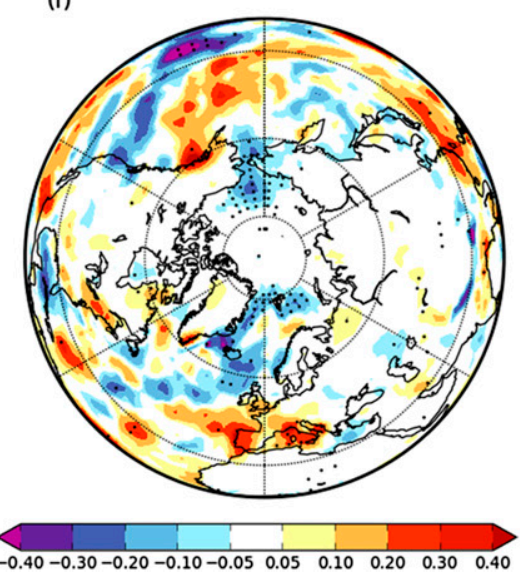

FIG. 9. Precipitation minus evaporation $\left(\mathrm{mm} \mathrm{day}^{-1}\right)$ in (a) CTL and (b) difference RED minus CTL for summer (JAS). (c),(d) As in (a),(b), but for autumn (OND). (e),(f) As in (a),(b), but for winter (JFM). In the difference plots the black dots indicate where the response is significant at the $95 \%$ level according to a Wilcoxon test.

therefore with the large-scale circulation response shown in Figs. $6 \mathrm{~b}$ and $7 \mathrm{~b}$. Furthermore, some areas of the North Pacific, western Siberia, and around Greenland experience a slight decrease of synoptic activity.

In autumn the response is stronger compared to summer; significant decreases in synoptic activity occur over most Arctic sea ice areas and surrounding land areas including large parts of northern North America, northern Europe, and northern Siberia as well as some sea areas in the North Atlantic and North Pacific (Fig. 11d). Decreases reach up to around $10 \%$ in the southern Beaufort Sea and over northwestern Siberia. 
(a)

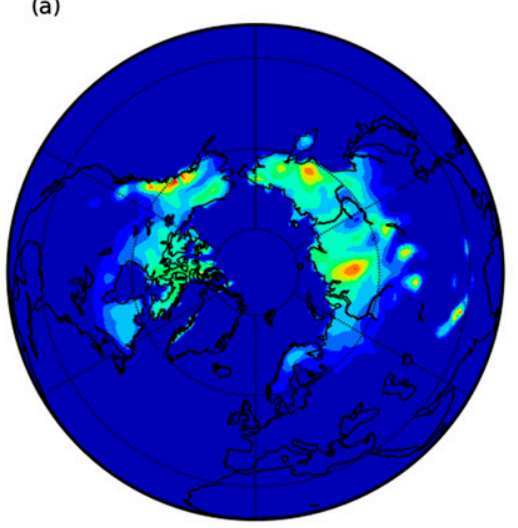

(c)

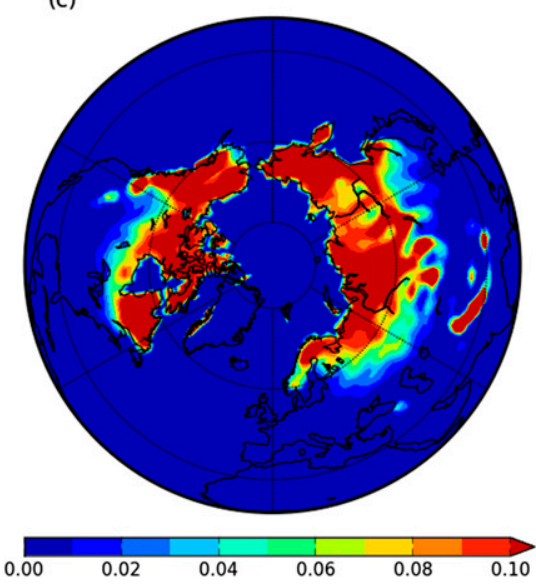

(b)

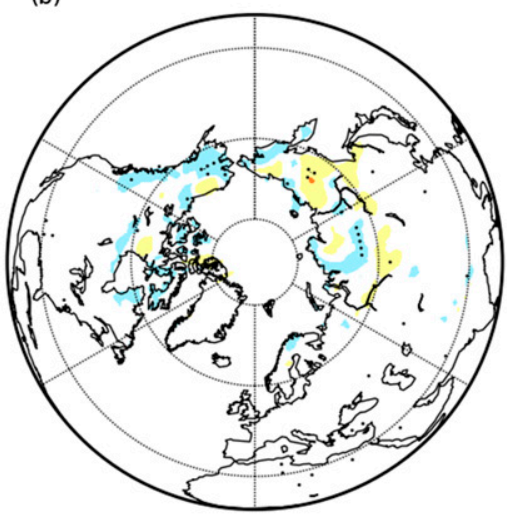

(d)

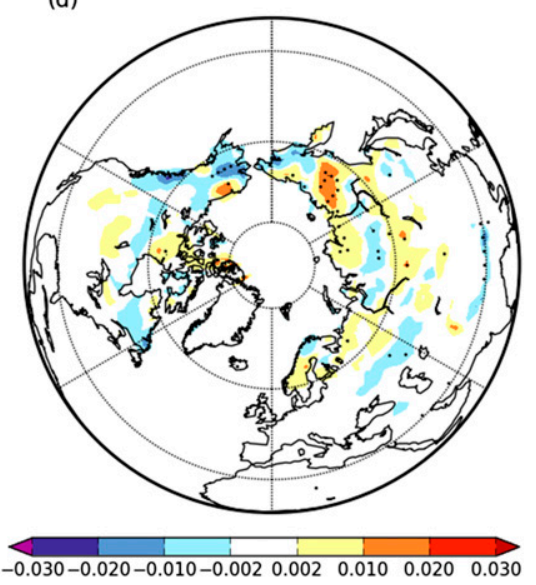

FIG. 10. Snow thickness ( $m$ water equivalent) in (a) CTL and (b) difference RED minus CTL for autumn (OND). (c),(d) As in (a),(b), but for winter (JFM). In the difference plots the black dots indicate where the response is significant at the $95 \%$ level according to a Wilcoxon test.

In winter the response is weaker than in autumn but still stronger than in summer; significant reductions of synoptic activity of around 5\% can be seen around the Fram Strait and south of it, northwest of Greenland, and over the Beaufort Sea (Fig. 11f). Autumn and winter responses are only partly consistent with a shift toward a negative NAO index since the increases in the Mediterranean storm track are not significant.

An alternative approach that we used to investigate changes in storm tracks is to track and count cyclones (see section $2 \mathrm{~b}$ ). The total annual number of cyclones over the Northern Hemisphere $(\mathrm{NH})$ in both the CTL and RED experiments is 1360 ( \pm 32 in CTL and \pm 49 in RED) (no figure shown; the uncertainty is given as standard deviation of the annual number of cyclones). This is about $3 \%$ less than found in the NCEP-DOE reanalysis (Tilinina et al. 2013). This reanalysis has a similar spectral resolution (T62L28) to our model experiments (T63L47) and shows on average $\sim 1390$ cyclones per year over the NH (Tilinina et al. 2013). The positioning of the major storm tracks in the North Atlantic and the North Pacific as well as over Mediterranean is also consistent with the NCEP-DOE and other reanalyses (Tilinina et al. 2013), with enhanced midlatitude storm tracks in winter and autumn and intensified Mediterranean storm tracks in summer (Figs. 12a,c,e).

The spatial response pattern of the number of cyclones to sea ice loss is presented in Figs. 12b, 12d, and $12 \mathrm{f}$. During summer and especially autumn there is an evident decrease of the number of cyclones over the Arctic in RED compared to CTL. During winter, the response is partly opposite with approximately $20 \%$ (1-2 cyclones per winter season) more cyclones over the eastern Arctic in RED compared to CTL.

It should be noted that responses in the MSLP synoptic activity (Fig. 11) and in cyclone counts (Fig. 12) are not necessarily the same since the MSLP synoptic 
(a)

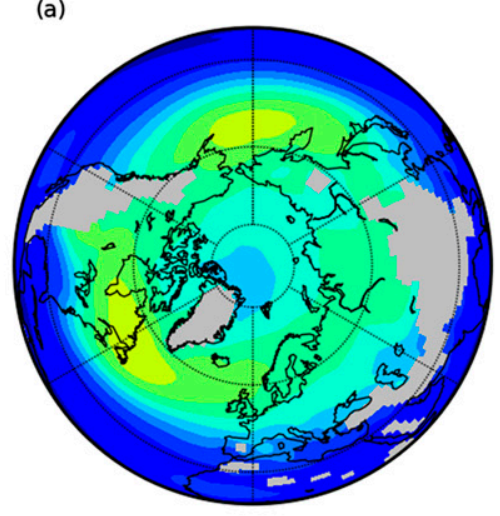

(c)

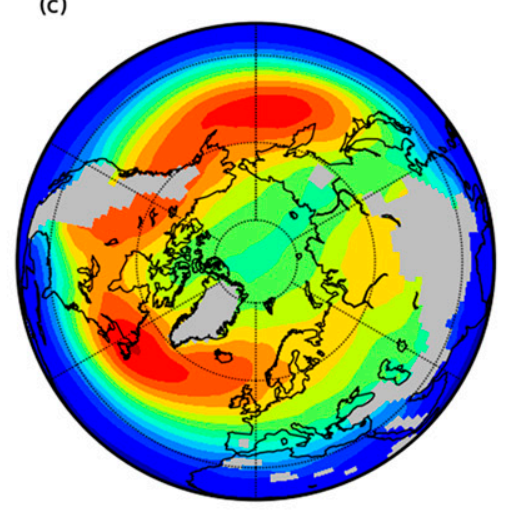

(e)

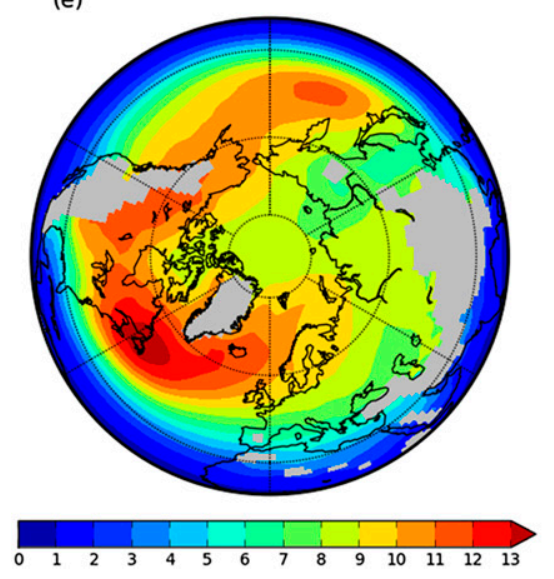

(b)

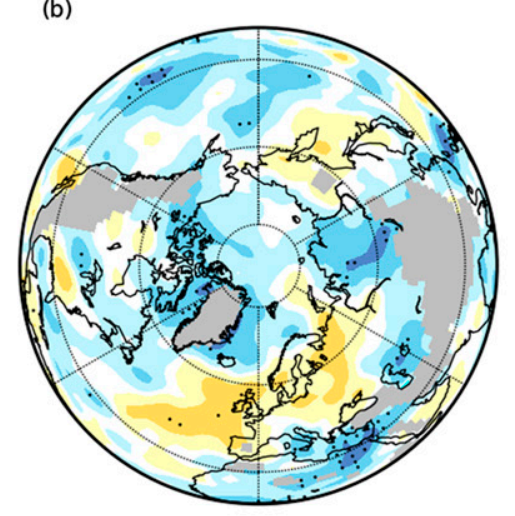

(d)

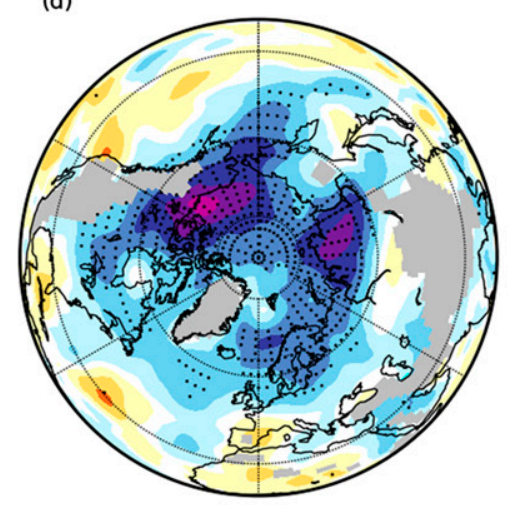

(f)

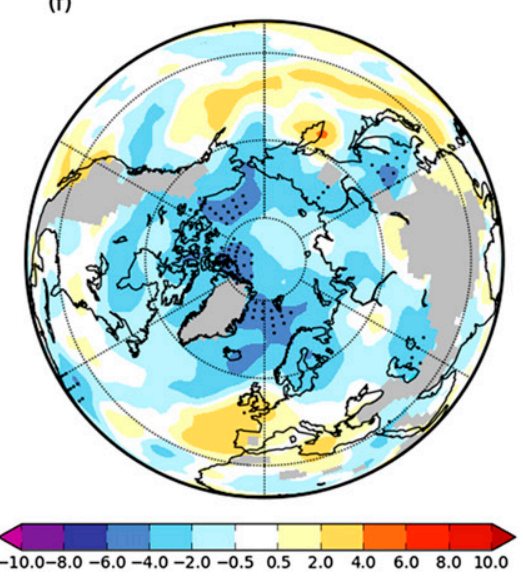

FIG. 11. Synoptic activity (hPa) calculated as standard deviation of high-pass filtered mean sea level pressure data in (a) CTL and (b) relative difference RED minus CTL (\%) for summer (JAS). (c),(d) As in (a),(b), but for autumn (OND). (e),(f) As in (a),(b), but for winter (JFM). Values are only shown for grid points where Earth's surface is below $1000 \mathrm{~m}$ above sea level to exclude unrealistic values due to extrapolation. In the difference plots the black dots indicate where the response is significant at the $95 \%$ level according to a Wilcoxon test.

activity would additionally measure changes in high pressure regimes, which is not the case for cyclone counts. Furthermore, quasi-stationary or slow-moving cyclones (e.g., north of Greenland) may have an impact not on the synoptic activity but rather on the number of cyclones.

Consistent with characteristics of synoptic activity (Fig. 11), surface temperature gradients (Fig. 4), $P-E$ 
a) CTL, JAS

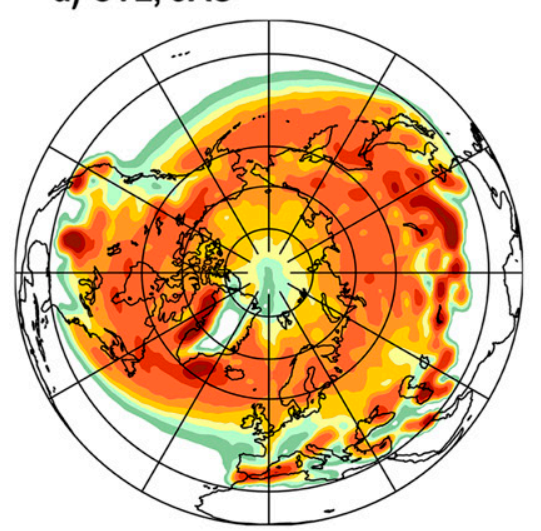

c) CTL, OND

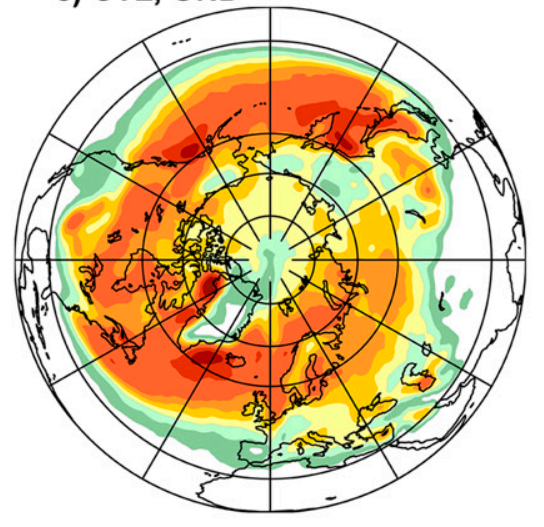

e) CTL, JFM

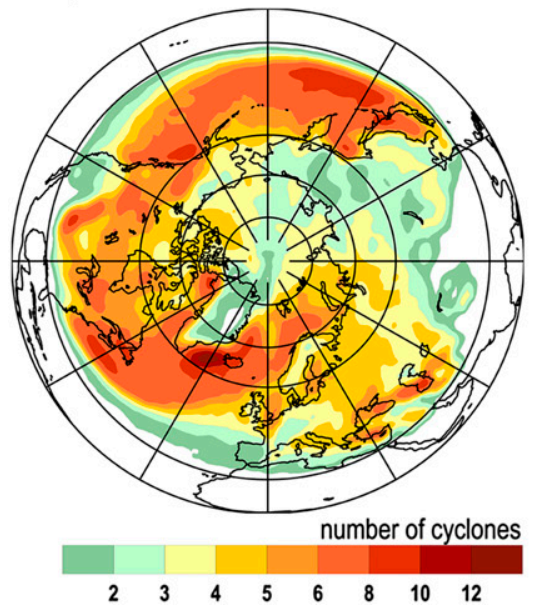

b) RED minus CTL, JAS

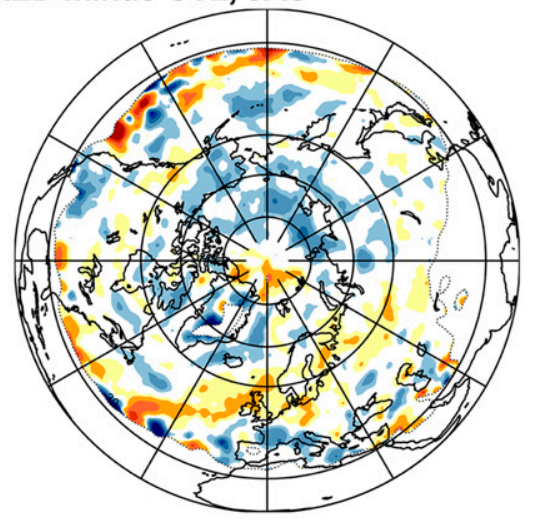

d) RED minus CTL, OND

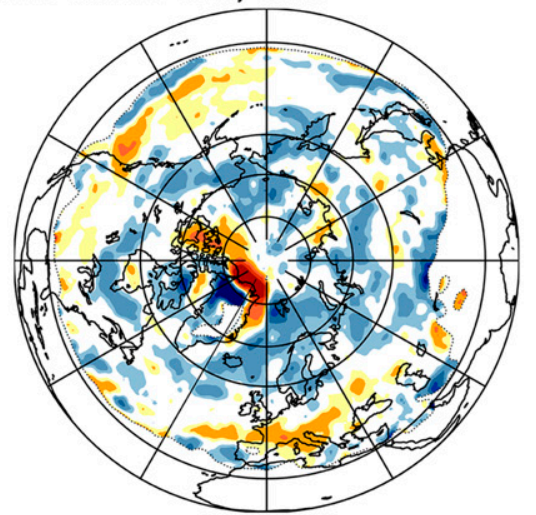

f) RED minus CTL, JFM

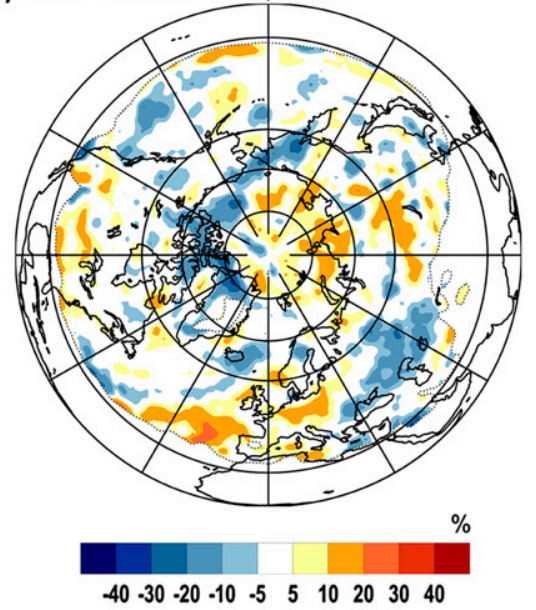

FIG. 12. Seasonal number of cyclones per $2^{\circ}$ radius circle $\left(\sim 155000 \mathrm{~km}^{2}\right)$ in (a) CTL and (b) relative difference RED minus CTL (\%) for summer (JAS). (c),(d) As in (a),(b), but for autumn (OND). (e),(f) As in (a),(b), but for winter (JFM).

(Fig. 9), and the large-scale circulation (Figs. 6 and 7), the strongest response in the number of cyclones [about $20 \%-30 \%$, or $2-3$ cyclones per autumn season, reduction in RED compared to CTL in the GreenlandIceland-Norwegian (GIN) Seas and subpolar North
Pacific] is identified in autumn (Fig. 12d), when the Arctic surface temperature increase is the strongest. At the same time, Mediterranean and subtropical Pacific storm tracks are enhanced in the RED experiment, showing $20 \%-30 \%$ ( 1 cyclone per autumn season) more 

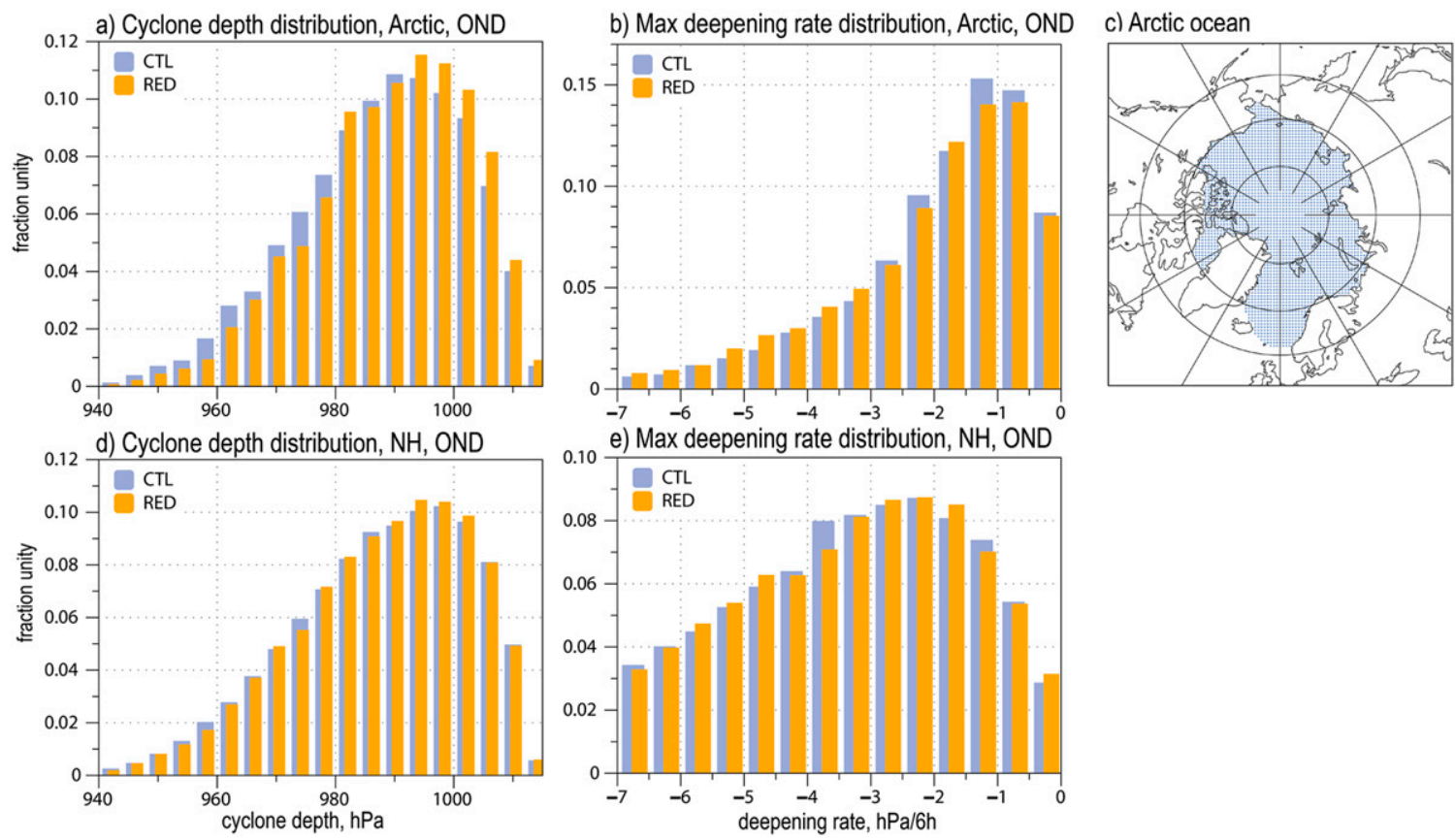

FIG. 13. (a) Cyclone depth distribution in CTL and RED experiments for autumn (OND) in the Arctic. (b) As in (a), but showing maximum deepening rate distribution. (c) Definition of the Arctic. (d),(e) As in (a),(b), but in the Northern Hemisphere. Please note the different scales in (b) and (e).

cyclones compared to CTL. This implies a southward shift of the midlatitude storm tracks in autumn.

It is interesting to note also the strongly localized autumn response over the western Arctic north of Greenland with $40 \%$ (2-3 cyclones per autumn season) more cyclones and corresponding negative differences over northern Greenland (Fig. 12d). This likely hints at a northward shift of the local cyclone pass; however, this phenomenon should be considered with caution because of potentially large uncertainties of cyclone identification in this area in most numerical algorithms, including ours (Rudeva et al. 2014, their Fig. 8). Given the agreement of the results of our model experiment with those revealed by global reanalyses we expect the results to be qualitatively realistic, while quantitatively the coupled signal in cyclone characteristics might be underestimated due to model limitations implied by the spatial resolution.

\section{f. Cyclone life cycle}

To further analyze cyclone activity response to the Arctic sea ice loss in the set of RED experiments we demonstrate probability distributions of cyclone central pressure and deepening rates (Fig. 13) for the autumn over the Arctic Ocean and over the NH. These parameters characterize cyclone intensity and development, both being sensitive to sea-air interaction processes.
Thus, they can potentially capture the storm track responses to the intensified air-sea heat and moisture fluxes over the ice-free ocean.

Our results show that in the RED experiments (reduced ice) over the Arctic Ocean cyclones tend to become shallower (Fig. 13a) and demonstrate stronger deepening rates (Fig. 13b). According to a KolmogorovSmirnov test (K-S test; Kolmogorov 1933; Smirnov 1948) the difference between the distributions revealed by RED and CTL is significant at the $95 \%$ level. The fraction of cyclones deeper than $980 \mathrm{hPa}$ over the Arctic in the RED experiments is smaller than in CTL ( $12 \%$ vs $15 \%)$. This effect is likely the result of the southward shift of the storm track (Fig. 12d). The percentages of moderately $\left[>3 \mathrm{hPa}(6 \mathrm{~h})^{-1}\right]$ and rapidly [ $>6 \mathrm{hPa}$ $(6 \mathrm{~h})^{-1}$ ] deepening cyclones in the RED experiments (18\% and $4 \%$ respectively) are larger than in CTL $(15 \%$ and $3 \%$ ). Thus, while the Arctic cyclones are generally shallower in the RED experiments, they tend to intensify more rapidly than in CTL. Note that probability distributions of cyclone life cycle parameters (central pressure and deepening rates) built for the whole Northern Hemisphere (Figs. 13d,e) are very close to each other, and not distinguishable according to a K-S test.

A measure for the potential development and intensification of low pressure systems has been proposed 
by Eady (1949) and has been widely applied in previous studies. This Eady index or maximum Eady growth rate comprises a combination of vertical stability and vertical wind shear:

$$
\mathrm{EADY}=-0.31\left|\frac{f}{N}\right| g\left(\frac{p}{R T}\right)\left|\frac{d U}{d p}\right|,
$$

with EADY being the maximum Eady growth rate, $f$ the Coriolis parameter, $N$ the Brunt-Väisälä frequency, $p$ the pressure in the middle of an atmospheric layer, $R$ the gas constant for dry air $\left(287 \mathrm{~J} \mathrm{~kg}^{-1} \mathrm{~K}^{-1}\right), T$ the temperature in the middle of the atmospheric layer, and $d U / d p$ the change of horizontal wind speed with pressure as vertical coordinate. The vertical stability is expressed by $f / N$ while the vertical wind shear is accounted for by the remaining terms. In our analysis we used the atmospheric layer between 850 and $500 \mathrm{hPa}$ and approximated the middle of that layer as $700 \mathrm{hPa}$. We obtained qualitatively similar results with atmospheric layers between 850 and $700 \mathrm{hPa}$ or between 700 and $500 \mathrm{hPa}$.

In Fig. 14 the maximum Eady growth rate in CTL as well as the response RED minus CTL is shown. Differences are generally below $5 \%$ and only in small areas statistically significant. In summer the main response can be seen in the middle latitudes of Europe (Fig. 14b). This area of a stronger maximum Eady growth rate is the area where the strongest increases in the pressure gradient, the cyclone count, and $P-E$ are simulated, indicating an intensified midlatitude storm track. In contrast, the subtropical Mediterranean storm track is weakened.

In autumn the picture changes: subtropical storm tracks are intensified and midlatitude storm tracks weakened (Fig. 14d) as was already identified from the cyclone number response. Therefore, negative maximum Eady growth rate responses can be seen over the northern North Atlantic and the northern North Pacific as well as adjacent land areas while positive maximum Eady growth rate responses can be seen over parts of and south of the Mediterranean Sea as well as over parts of the North Pacific and North Atlantic between around $40^{\circ}$ and $50^{\circ} \mathrm{N}$. Furthermore, in some high latitudes such as over the Canadian Arctic and north and east of Greenland positive responses are simulated, which do not necessarily translate into larger cyclone counts or increased synoptic activity-in contrast, decreased synoptic activity is simulated there while cyclone count responses are partly negative and partly positive. The southward shift of storm tracks with increased maximum Eady growth rate close to $40^{\circ} \mathrm{N}$ persists into winter (Fig. 14f), although these changes are hardly significant. Other areas do not show any significant responses apart from a negative response in some parts of western Canada.

When separately investigating the two factors contributing to the maximum Eady growth rate (i.e., vertical stability and vertical wind shear; not shown), it turns out that in autumn and winter over the Arctic a reduced vertical stability and a reduced vertical wind shear counteract and lead to no significant or positive Eady growth rate responses over the Arctic. Here the reduced vertical stability appears to be of no importance for synoptic activity as can be seen from the negative synoptic activity response. Instead, it is the reduced vertical wind shear that manifests itself in the synoptic activity response.

Over the midlatitudes no significant change in the vertical stability can be found in our RED compared to our CTL experiments. The vertical wind shear responses in the midlatitudes with decreases in many regions north of around $50^{\circ} \mathrm{N}$ and increases south of it in the Pacific and western Atlantic sectors as well as in the Mediterranean area are comparable to but more significant than the responses in the Eady growth rate. Therefore, it can be concluded that in our setup of experiments the change in the vertical wind shear is more relevant for the actual synoptic activity than the change in the vertical stability. The decrease of vertical stability may be responsible for the stronger deepening rates of the cyclones in the Arctic.

\section{Discussion and conclusions}

We studied the responses of a reduction of Arctic sea ice on the atmospheric circulation characteristics with a coupled model performing 1-yr-long experiments. Our model setup is quite similar to the one employed by Petrie et al. (2015) but with important differences: they introduce the sea ice thickness reduction already on 1 April and they do not have a seasonally ice-free Arctic but rather resemble Arctic sea ice conditions in recent summers with record low sea ice concentrations such as 2007 and 2012. When interpreting the responses to reduced Arctic sea ice we have to consider that changes in the Arctic sea ice conditions are small in winter and spring compared to summer and autumn due to the recovery mechanism of the Arctic sea ice described by Tietsche et al. (2011). It is relevant to study the impact of such seasonally different decreases in Arctic sea ice since observations of the last 32 years indicate such a behavior (Keen et al. 2013). It should be noted that all results are subject to model uncertainties and the ability to reproduce observed coupled processes.

The large-scale circulation responses in the sensitivity experiment depend on the season considered and are small (up to $2 \mathrm{hPa}$ in MSLP and $30 \mathrm{~m}$ in Z500) compared 
(a)

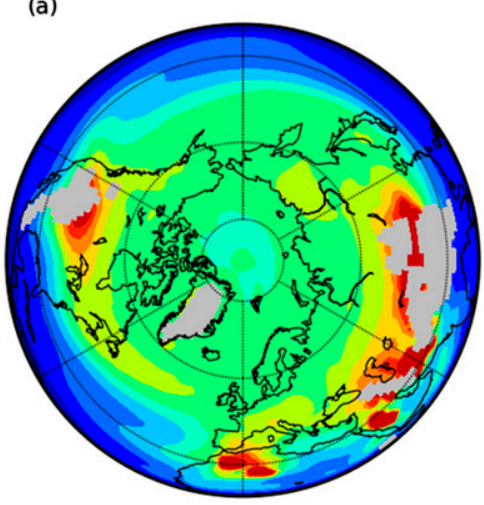

(c)

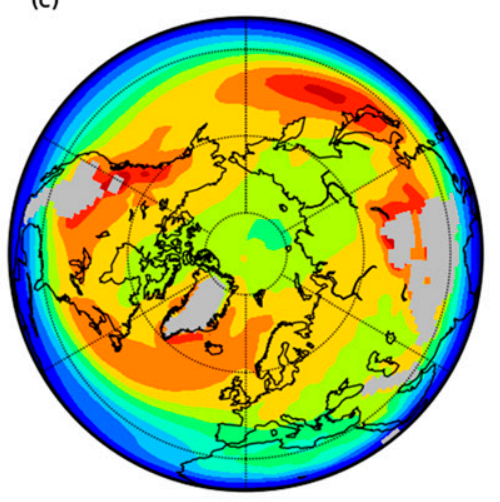

(e)
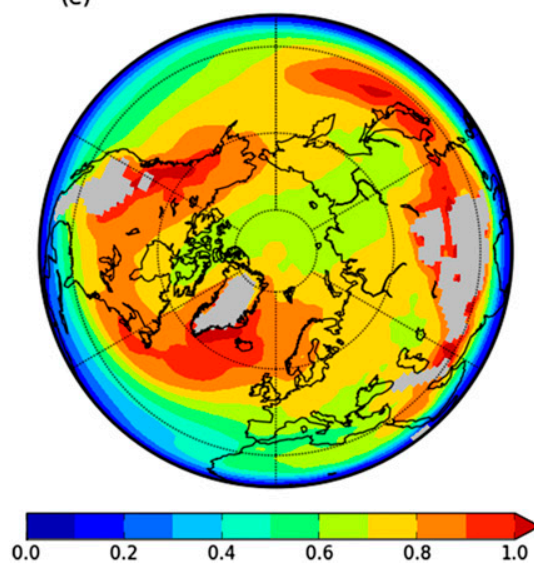

(b)

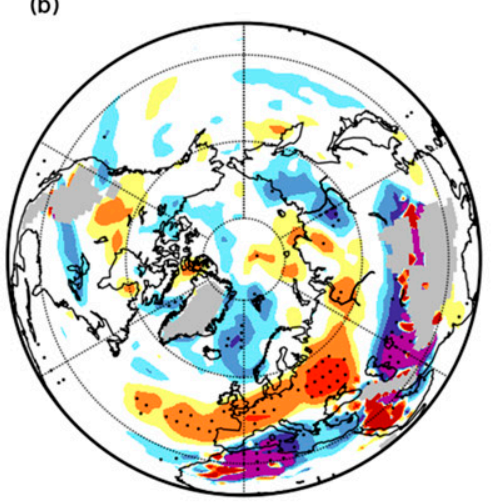

(d)

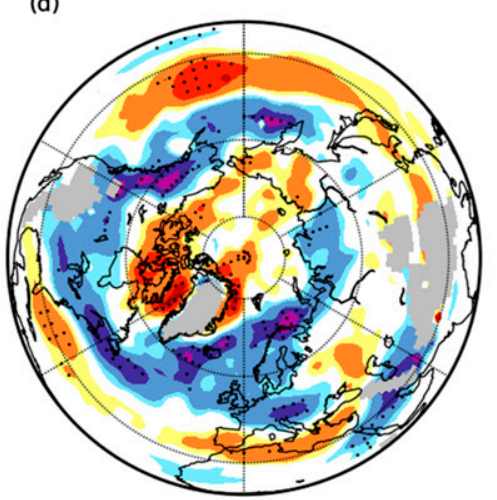

(f)

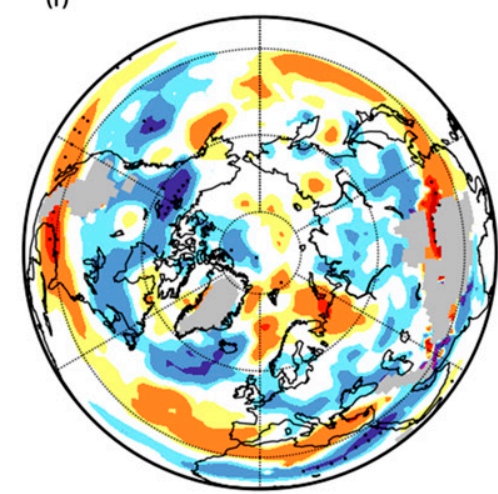

$-0.030-0.020-0.010-0.0050 .005 \quad 0.0100 .020 \quad 0.030$

FIG. 14. Maximum Eady growth rate $\left(1 \mathrm{day}^{-1}\right)$ between 850 and $500 \mathrm{hPa}$ in (a) CTL and (b) difference RED minus CTL for summer (JAS). (c),(d) As in (a),(b), but for autumn (OND). (e),(f) As in (a),(b), but for winter (JFM). Values are only shown for grid points where Earth's surface is below $1500 \mathrm{~m}$ above sea level to exclude unrealistic values due to extrapolation. In the difference plots the black dots indicate where the response is significant at the $95 \%$ level according to a Wilcoxon test.

to observed interannual variabilities (according to observations up to around $5 \mathrm{hPa}$ in MSLP and $50 \mathrm{~m}$ in Z700; see, e.g., Chervin 1986). The fact that some of these anomalies are still statistically significant is a result of the relatively large ensemble size used. The general feature of decreased westerly flow in autumn and winter as a response to reduced Arctic sea ice cover has been reported in various previous studies such as Semmler 
et al. (2016), Deser et al. (2015), Jaiser et al. (2012), and many more. However, not all previous studies agree on this: for example, circulation changes in the coupled 1-yr experiments performed by Petrie et al. (2015) show quite different response patterns emphasizing how sensitive large-scale circulation responses may be to different experiment setups and different model formulations.

Winter large-scale circulation changes such as a shift toward the negative phase of the $\mathrm{AO} / \mathrm{NAO}$ as well as a consistent shift of the storm track to the south have been suggested as a consequence of increased Eurasian autumn snow cover after summers with low Arctic sea ice extent (Cohen et al. 2012, 2014). However, we cannot confirm this relationship between autumn snow cover and large-scale circulation as we could not identify significant changes in autumn snow cover as a response to the reduced Arctic summer sea ice cover. The identified southward shift of the storm track is therefore more likely due to the sea ice loss and not to the autumn snow cover change, which is confirmed by Semmler et al (2016) from short numerical weather prediction (NWP) model simulations.

It is interesting to note that coupled global climate model projections with increasing greenhouse gas concentrations generally show a northward shift of the storm track (Löptien et al. 2008; Ulbrich et al. 2009; Woollings et al. 2012). In these projections there is enhanced upper tropospheric warming in the tropics leading to an enhanced meridional temperature gradient in the upper troposphere. This may counteract the influence of a reduced meridional temperature gradient in the lower troposphere due to the decreasing Arctic sea ice cover.

While we found reduced synoptic activity and fewer cyclones in the Arctic in autumn, maximum Eady growth rate and cyclone deepening rates slightly increased especially around Greenland as a response to reduced Arctic sea ice. It is important to note that a stronger maximum Eady growth rate does not automatically translate into stronger synoptic activity outside the main baroclinic zones in areas such as the Arctic. More specifically, increasing maximum Eady growth rates in the past 20 years, as seen by Jaiser et al. (2012) in the Siberian Arctic as a response to decreasing Arctic sea ice, should not be interpreted as an increase in synoptic activity. We hypothesize that the weakened meridional temperature gradient and reduced vertical wind shear is the driver behind reduced cyclone activity while the decreased vertical stability increases levels of atmospheric humidity (and hence diabatic forcing), which can potentially trigger stronger cyclone intensification once a system has generated.
In winter some cooling of around $0.5 \mathrm{~K}$, albeit marginally significant, was simulated in some regions of North America and Eurasia in response to reduced Arctic sea ice. Such a cooling due to sea ice reduction and associated weaker westerly flow (negative phase of $\mathrm{AO} / \mathrm{NAO}$ ) and less maritime influence or tropospherestratosphere coupling is consistent with previous studies, although uncertainty remains (Walsh 2014; Vihma 2014). We conclude that the cooling effect is rather small compared to the variability of the system, locally very limited, and mostly insignificant. Furthermore, the highlatitude warming and the associated milder air advected in situations with northerly flow would counteract a possible cooling due to less maritime influence.

One additional outcome, which is interesting from an oceanographic perspective, is the decrease in precipitation minus evaporation $(P-E)$ over the entire Arctic in summer and especially autumn, indicating a decrease in lateral moisture transport into the Arctic-consistent with Singarayer et al. (2006) from atmosphere-only simulations with end-of-the-century sea ice conditions. This is consistent with reduced synoptic activity due to a reduced meridional temperature gradient or reduced planetary wave activity. The decrease in Arctic $P-E$ may have important consequences for the surface salinity and therefore the stratification of the upper ocean and could influence the Arctic Ocean circulation. The increase in $P-E$ over the Mediterranean Sea in autumn and winter, which may be caused by the southward shift of the storm track and associated increased synoptic activity in that area, may be of importance for the surface salinity and stratification of the upper Mediterranean Sea layer. Similarly to the phase of the AO/NAO or the location of the storm tracks, the decreasing Arctic sea ice seems to counteract the impact of tropical warming on Arctic $P-E$. This can be concluded because previous studies such as Bintanja and Selten (2014) report an increase in Arctic $P-E$ in climate change projections for the twenty-first century.

Finally we would like to note that our 1-yr simulations are too short to show a strong oceanic response. Sea surface temperature and sea surface salinity exhibit only small differences outside the Arctic Ocean (mostly below $0.1 \mathrm{~K}$ and $0.1 \mathrm{psu}$, respectively). This is in contrast to the recent results obtained by Petrie et al. (2015), who reported significant remote SST increases especially in the northwestern North Atlantic and in the northern North Pacific as a response to sea ice thickness reductions on 1 April. It is not clear if the different start date (in our study 1 June) or the different model could lead to these discrepancies. These discrepancies may also contribute to the different atmospheric large-scale 
circulation responses in our and their studies. In autumn some limited changes toward a weaker circulation in the GIN Seas and in winter toward a weaker North Atlantic subpolar gyre as expressed by sea surface height (SSH) increases by up to $0.02 \mathrm{~m}$ can be seen. Given these results, on this short time scale the oceanic feedback on the atmosphere can be regarded as small. Results of century-long coupled experiments indicate that substantial oceanic changes arise on such a long time scale, which can in turn influence the atmospheric circulation. We plan to publish results of those experiments in a separate paper.

Acknowledgments. We are grateful to the HLRN (Northern German High Performance Computing Centre) for granting us computational resources for carrying out the simulations. Furthermore we acknowledge our colleagues from the Max Planck Institute for Meteorology in Hamburg and from the Alfred Wegener Institute involved in the development of ECHAM6 and FESOM as well as their coupling. NT and SKG benefited from the grant of the Russian Science Foundation 14-37-00038 and LS from an ERASMUS scholarship. We would like to thank four anonymous reviewers for helpful comments.

\section{REFERENCES}

Akima, H., 1970: A new method of interpolation and smooth curve fitting based on local procedures. J. Assoc. Comput. Mach., 17, 589-602, doi:10.1145/321607.321609.

Bader, J., M. D. Mesquita, K. I. Hodges, N. Keenlyside, S. Østerhus, and M. Miles, 2011: A review on Northern Hemisphere sea-ice, storminess and the North Atlantic Oscillation: Observations and projected changes. Atmos. Res., 101, 809-834, doi:10.1016/j.atmosres.2011.04.007.

Barnston, A. G., and R. E. Livezey, 1987: Classification, seasonality, and persistence of low-frequency atmospheric circulation patterns. Mon. Wea. Rev., 115, 1083-1126, doi:10.1175/ 1520-0493(1987)115<1083:CSAPOL >2.0.CO;2.

Bintanja, R., and F. Selten, 2014: Future increases in Arctic precipitation linked to local evaporation and sea-ice retreat. Nature, 509, 479-482, doi:10.1038/nature13259.

Blackmon, M. L., 1976: A climatological spectral study of the 500-mb geopotential height of the Northern Hemisphere. J. Atmos. Sci., 33, 1607-1623, doi:10.1175/1520-0469(1976)033<1607: ACSSOT $>2.0 . \mathrm{CO} ; 2$.

Budikova, D., 2009: Role of Arctic sea ice in global atmospheric circulation: A review. Global Planet. Change, 68, 149-163, doi:10.1016/j.gloplacha.2009.04.001.

Chervin, R. M., 1986: Interannual variability and seasonal climate predictability. J. Atmos. Sci., 43, 233-251, doi:10.1175/ 1520-0469(1986)043<0233:IVASCP > 2.0.CO;2.

Chiang, J. C., and C. M. Bitz, 2005: Influence of high latitude ice cover on the marine intertropical convergence zone. Climate Dyn., 25, 477-496, doi:10.1007/s00382-005-0040-5.

Cohen, J. L., J. C. Furtado, M. A. Barlow, V. A. Alexeev, and J. E. Cherry, 2012: Arctic warming, increasing snow cover and widespread boreal winter cooling. Environ. Res. Lett., 7, 014007, doi:10.1088/1748-9326/7/1/014007.

— treme mid-latitude weather. Nat. Geosci., 7, 627-637, doi:10.1038/ngeo2234.

Deser, C., R. A. Tomas, and S. Peng, 2007: The transient atmospheric circulation response to North Atlantic SST and sea ice anomalies. J. Climate, 20, 4751-4767, doi:10.1175/ JCLI4278.1.

,-- M. Alexander, and D. Lawrence, 2010: The seasonal atmospheric response to projected Arctic sea ice loss in the late twenty-first century. J. Climate, 23, 333-351, doi:10.1175/ 2009JCLI3053.1.

,,-- and L. Sun, 2015: The role of ocean-atmosphere coupling in the zonal-mean atmospheric response to Arctic sea ice loss. J. Climate, 28, 2168-2186, doi:10.1175/JCLI-D-14-00325.1.

Eady, E., 1949: Long waves and cyclone waves. Tellus, 1, 33-52, doi:10.1111/j.2153-3490.1949.tb01265.x.

Francis, J. A., and S. J. Vavrus, 2012: Evidence linking Arctic amplification to extreme weather in mid-latitudes. Geophys. Res. Lett., 39, L06801, doi:10.1029/2012GL051000.

Gulev, S. K., M. Latif, N. Keenlyside, W. Park, and K. P. Koltermann, 2013: North Atlantic Ocean control on surface heat flux on multidecadal timescales. Nature, 499, 464-467, doi:10.1038/nature12268.

Hezel, P., T. Fichefet, and F. Massonnet, 2014: Modeled Arctic sea ice evolution through 2300 in CMIP5 extended RCPs. Cryosphere, 8, 1195-1204, doi:10.5194/tc-8-1195-2014.

Honda, M., J. Inoue, and S. Yamane, 2009: Influence of low Arctic sea-ice minima on anomalously cold Eurasian winters. Geophys. Res. Lett., 36, L08707, doi:10.1029/2008GL037079.

Jaiser, R., K. Dethloff, D. Handorf, A. Rinke, and J. Cohen, 2012: Impact of sea ice cover changes on the Northern Hemisphere atmospheric winter circulation. Tellus, 64A, 11595, doi:10.3402/ tellusa.v64i0.11595.

Jung, T., 2005: Systematic errors of the atmospheric circulation in the ECMWF forecasting system. Quart. J. Roy. Meteor. Soc., 131, 1045-1073, doi:10.1256/qj.04.93.

— S. Gulev, I. Rudeva, and V. Soloviov, 2006: Sensitivity of extratropical cyclone characteristics to horizontal resolution in the ECMWF model. Quart. J. Roy. Meteor. Soc., 132, 18391858, doi:10.1256/qj.05.212.

_ - M. A. Kasper, T. Semmler, and S. Serrar, 2014: Arctic influence on subseasonal midlatitude prediction. Geophys. Res. Lett., 41, 3676-3680, doi:10.1002/2014GL059961.

Keen, A. B., H. T. Hewitt, and J. K. Ridley, 2013: A case study of a modelled episode of low Arctic sea ice. Climate Dyn., 41 1229-1244, doi:10.1007/s00382-013-1679-y.

Kolmogorov, A. N., 1933: Sulla determinazione empirica di una legge di distribuzione. G. Ist. Ital. Attuari, 4, 83-91.

Kravtsov, S., and S. K. Gulev, 2013: Kinematics of eddy-mean flow interaction in an idealized atmospheric model. J. Atmos. Sci., 70, 2574-2595, doi:10.1175/JAS-D-12-0309.1.

Lindsay, R., and A. Schweiger, 2015: Arctic sea ice thickness loss determined using subsurface, aircraft, and satellite observations. Cryosphere, 9, 269-283, doi:10.5194/tc-9-269-2015.

Löptien, U., O. Zolina, S. K. Gulev, M. Latif, and V. Soloviov, 2008: Cyclone life cycle characteristics over the Northern Hemisphere in coupled GCMs. Climate Dyn., 31, 507-532, doi:10.1007/s00382-007-0355-5.

Neiman, P. J., and M. Shapiro, 1993: The life cycle of an extratropical marine cyclone. Part I: Frontal-cyclone evolution and thermodynamic air-sea interaction. Mon. Wea. 
Rev., 121, 2153-2176, doi:10.1175/1520-0493(1993)121<2153: TLCOAE $>2.0 . C O ; 2$.

Neu, U., and Coauthors, 2013: IMILAST: A community effort to intercompare extratropical cyclone detection and tracking algorithms. Bull. Amer. Meteor. Soc., 94, 529-547, doi:10.1175/ BAMS-D-11-00154.1.

Osborn, T. J., 2006: Recent variations in the winter North Atlantic Oscillation. Weather, 61, 353-355, doi:10.1256/wea.190.06.

Peings, Y., and G. Magnusdottir, 2014: Response of the wintertime Northern Hemisphere atmospheric circulation to current and projected Arctic sea ice decline: A numerical study with CAM5 J. Climate, 27, 244-264, doi:10.1175/JCLI-D-13-00272.1.

Perlwitz, J., M. Hoerling, and R. Dole, 2015: Arctic tropospheric warming: Causes and linkages to lower latitudes. J. Climate, 28, 2154-2167, doi:10.1175/JCLI-D-14-00095.1.

Perovich, D. K., S. Gerland, S. Hendricks, W. Meier, M. Nicolaus, and M. Tschudi, 2014: Sea ice. Arctic Report Card 2014. NOAA. [Available online at http://www.arctic.noaa.gov/report14/.]

Petoukhov, V., and V. A. Semenov, 2010: A link between reduced Barents-Kara sea ice and cold winter extremes over northern continents. J. Geophys. Res., 115, D21111, doi:10.1029/ 2009JD013568.

Petrie, R. E., L. C. Shaffrey, and R. T. Sutton, 2015: Atmospheric impact of Arctic sea ice loss in a coupled ocean-atmosphere simulation. J. Climate, 28, 9606-9622, doi:10.1175/JCLI-D-15-0316.1.

Rind, D., R. Healy, C. Parkinson, and D. Martinson, 1995: The role of sea ice in $2 \times \mathrm{CO}_{2}$ climate model sensitivity. Part I: The total influence of sea ice thickness and extent. J. Climate, 8, 449-463, doi:10.1175/1520-0442(1995)008<0449:TROSII >2.0.CO;2.

Rudeva, I., and S. K. Gulev, 2011: Composite analysis of North Atlantic extratropical cyclones in NCEP-NCAR reanalysis data. Mon. Wea. Rev., 139, 1419-1446, doi:10.1175/2010MWR3294.1.

,$- \ldots$ I. Simmonds, and N. Tilinina, 2014: The sensitivity of characteristics of cyclone activity to identification procedures in tracking algorithms. Tellus, 66A, 24961, doi:10.3402/tellusa.v66.24961.

Scinocca, J., M. Reader, D. Plummer, M. Sigmond, P. Kushner, T. Shepherd, and A. Ravishankara, 2009: Impact of sudden Arctic sea-ice loss on stratospheric polar ozone recovery. Geophys. Res. Lett., 36, L24701, doi:10.1029/2009GL041239.

Screen, J. A., I. Simmonds, C. Deser, and R. Tomas, 2013: The atmospheric response to three decades of observed Arctic sea ice loss. J. Climate, 26, 1230-1248, doi:10.1175/JCLI-D-12-00063.1.

Semmler, T., R. McGrath, and S. Wang, 2012: The impact of Arctic sea ice on the Arctic energy budget and on the climate of the northern mid-latitudes. Climate Dyn., 39, 2675-2694, doi:10.1007/s00382-012-1353-9.

— - T. Jung, and S. Serrar, 2016: Fast atmospheric response to a sudden thinning of Arctic sea ice. Climate Dyn., 46, 1015-1025, doi:10.1007/s00382-015-2629-7.

Serreze, M. C., and A. P. Barrett, 2008: The summer cyclone maximum over the central Arctic Ocean. J. Climate, 21, 10481065, doi:10.1175/2007JCLI1810.1.

Sidorenko, D., and Coauthors, 2015: Towards multi-resolution global climate modeling with ECHAM6-FESOM. Part I:
Model formulation and mean climate. Climate Dyn., 44, 757780, doi:10.1007/s00382-014-2290-6.

Singarayer, J. S., J. L. Bamber, and P. J. Valdes, 2006: Twenty-firstcentury climate impacts from a declining Arctic sea ice cover. J. Climate, 19, 1109-1125, doi:10.1175/JCLI3649.1.

Smirnov, N., 1948: Table for estimating the goodness of fit of empirical distributions. Ann. Math. Stat., 19, 279-281, doi:10.1214/ aoms/1177730256

Stevens, B., and Coauthors, 2013: Atmospheric component of the MPI-M Earth System Model: ECHAM6. J. Adv. Model. Earth Syst., 5, 146-172, doi:10.1002/jame.20015.

Tietsche, S., D. Notz, J. H. Jungclaus, and J. Marotzke, 2011: Recovery mechanisms of Arctic summer sea ice. Geophys. Res. Lett., 38, L02707, doi:10.1029/2010GL045698.

Tilinina, N., S. K. Gulev, I. Rudeva, and P. Koltermann, 2013: Comparing cyclone life cycle characteristics and their interannual variability in different reanalyses. J. Climate, 26, 6419-6438, doi:10.1175/JCLI-D-12-00777.1.

Ulbrich, U., G. Leckebusch, and J. G. Pinto, 2009: Extra-tropical cyclones in the present and future climate: A review. Theor. Appl. Climatol., 96, 117-131, doi:10.1007/s00704-008-0083-8.

Valcke, S., T. Craig, and L. Coquart, Eds., 2013: OASIS3-MCT User Guide OASIS3-MCT 2.0. CERFACS/CNRS SUC URA Rep. 1875,50 pp.

Vihma, T., 2014: Effects of Arctic sea ice decline on weather and climate: A review. Surv. Geophys., 35, 1175-1214, doi:10.1007/ s10712-014-9284-0.

Walsh, J. E., 2014: Intensified warming of the Arctic: Causes and impacts on middle latitudes. Global Planet. Change, 117, 5263, doi:10.1016/j.gloplacha.2014.03.003.

Wang, Q., S. Danilov, D. Sidorenko, R. Timmermann, C. Wekerle, X. Wang, T. Jung, and J. Schröter, 2014: The Finite Element Sea Ice-Ocean Model (FESOM) v. 1.4: Formulation of an ocean general circulation model. Geosci. Model Dev., 7, 663 693, doi:10.5194/gmd-7-663-2014.

Woollings, T., J. M. Gregory, J. G. Pinto, M. Reyers, and D. J. Brayshaw, 2012: Response of the North Atlantic storm track to climate change shaped by ocean-atmosphere coupling. Nat. Geosci., 5, 313-317, doi:10.1038/ngeo1438.

Wu, B., J. Wang, and J. E. Walsh, 2006: Dipole anomaly in the winter Arctic atmosphere and its association with sea ice motion. J. Climate, 19, 210-225, doi:10.1175/JCLI3619.1.

Zhang, J., R. Lindsay, A. Schweiger, and M. Steele, 2013: The impact of an intense summer cyclone on 2012 Arctic sea ice retreat. Geophys. Res. Lett., 40, 720-726, doi:10.1002/grl.50190.

Zolina, O., and S. K. Gulev, 2002: Improving the accuracy of mapping cyclone numbers and frequencies. Mon. Wea. Rev., 130, 748-759, doi:10.1175/1520-0493(2002)130<0748:ITAOMC $>2.0 . C O ; 2$.

, and - 2003: Synoptic variability of ocean-atmosphere turbulent fluxes associated with atmospheric cyclones. J. Climate, 16, 2717-2734, doi:10.1175/1520-0442(2003)016<2717: SVOOTF $>2.0 . \mathrm{CO} ; 2$ 